\title{
Mutation Patterns Due to Converging Mitochondrial Replication and Transcription Increase Lifespan, and Cause Growth Rate-Longevity Tradeoffs
}

\author{
Hervé Seligmann \\ ${ }^{1}$ Herpetological Collection National Natural History Collections (NNHC), \\ The Hebrew University of Jerusalem, \\ ${ }^{2}$ Center for Ecological and Evolutionary Synthesis, \\ University of Oslo, \\ ${ }^{3}$ Department of Life Sciences, \\ Ben Gurion University, \\ 1,3Israel \\ ${ }^{2}$ Norway
}

\section{Introduction}

DNA replication and RNA transcription share many properties (Little et al., 1993; Hassan \& Cook, 1994; Marczynski and Shapiro 1995; Mohanty et al., 1996; Prado \& Aguilera 2005), notably in mitochondria (Nass 1995; Lee \& Clayton, 1997). The joint occurrence of transcription and replication on DNA apparently necessitates coordination (Gilbert, 2001; MacAlpine at al., 2004), among others because collisions occur between the replication and transcription complexes on the same DNA strand (Mirkin \& Mirkin, 2005). This coordination may be part of the regulation of gene expression (Patnaik, 1997) and the rates of both processes (Morton, 1999). This predicts the structural organization of genes on chromosomes around replication origins in relation to functional pressures (Schwaiger \& Schubeler, 2006): highly expressed genes are located close to replication origins, those expressed in few tissues are more distant (Huvet et al., 2007). Such functional pressures seem strong enough to cause convergences in genome organization between very distant organisms such as yeast (Saccharomyces cerevisiae) and Caulobacter, despite that the proteins involved in their replication and transcription are basically unrelated (Brazhnik \& Tyson, 2006). For that reason, transcription-associated genes are frequently located close to replication origins (Couturier and Rocha, 2006). The conserved arrangements of mitochondrial tRNA genes in vertebrates also seems to optimize between early replication of tRNAs whose anticodons have high probability to mutate in the single strand state (Seligmann et al., 2006a) and early transcription of tRNAs with frequently used cognate amino acids (Satoh et al., 2010). Note that this principle of optimizing between two competing processes exists also at the level of translation, between initiation and elongation (Xia et al., 2007), and might apply to many other molecular processes. 


\subsection{Replication and transcription in mitochondria}

Both mitochondrial rRNA genes, the only transcription genes coded by vertebrate mitochondrial genomes, are located next to the mitochondrial control region. Indeed, the mitochondrial D-loop, according to the frequently observed collinearity between replication and transcription in prokaryotes (Nikolaou \& Almirantis, 2005), includes the regions that initiate replication of the heavy strand $(\mathrm{OH})$ and transcription (Shadel \& Clayton, 1997; Fernandez-Silva et al., 2003), fitting the model that all transcription enhancers also enhance replication and vice versa (Boulikas, 1995). The major regulatory sequences in the D-Loop contain the only mitochondrial promoters, for both light- and heavy-strand transcription, in addition to the origin of heavy strand replication (Chang and Clayton, 1984). Biochemical evidence indicates that the primers generated by the light-strand promoter are used for replication priming (Chang \& Clayton, 1985; Chang et al., 1985). This close association between the two processes in mitochondria expresses itself by the fact that some Alzheimerassociated mutations in the mitochondrial control region suppress both mitochondrial replication and transcription (Coskun et al., 2004). Hence, mitochondria, because of their involvement in ageing (Martin \& Grotewiel 2006; Yu \& Chung 2006), are a good system in which to study the putative relationship existing between the connection (and level of connection) of replication and transcription with ageing processes.

\subsection{Mitochondria and ageing}

Several properties of mitochondrial genomes have already been shown to associate with lifespan, presumably because of cumulative DNA damage due to free radicals produced by the normal function of mitochondria in the cell's energetic metabolism (Wiesner et al., 2006). It seems that evolution of vertebrate longevities (and in general, the associated evolution of their life history strategies) causes accelerated rates of amino acid replacements in mitochondrion-encoded protein coding genes (Rottenberg, 2006, 2007). Mutagenesis independent of free oxidative radicals also affects mitochondrion-associated ageing: in mitochondrial genomes, the number of direct repeats, a factor causing deletions, correlates negatively with mammalian lifespan (Samuels, 2004; Samuels et al., 2004; Khaidakov et al., 2006). Using a similar comparative approach, Samuels (2005) showed that lifespan increases proportionally to the stability of hybridization between complementary mitochondrial DNA strands, estimated by free energies. This property is proportional to the probability of opening up and expansion of single-stranded mtDNA bubbles. Negative selection on repeats (Samuels, 2005; Khaidakov et al., 2006) explains the exceptional status of most vertebrate mitochondrial genomes as breaking Chargaff's second parity rule (complementary nucleotides are met with almost equal frequencies in single stranded DNA), fitting the hypothesis that inversions and inverted transposition could be a major contributing if not dominant factor in the almost universal validity of this rule (AlbrechtBuehler, 2006).

These single stranded bubbles are more likely to occur where direct repeats exist, causing deletions (Khaidakov et al., 2006), but this probably also increases mutation rates in the single stranded sequences forming the bubble when the bubble is not enzymatically excised. This is because hydrolytic deaminations of cytosine to thymine and adenine to guanine, both transitions, occur proportionally to time spent single stranded ( $\left.D_{\text {ssh }}\right)$ by the genome (as shown for example during replication in primate mitochondrial genomes, Krishnan et al., 2004a, b). 


\subsection{Developmental stabilities}

Developmental stabilities, typically estimated by the level of symmetry of bilateral traits (Seligmann, 2000) usually increase with correlates of fitness (Moller, 1997, 1999). Hence it is sensible that rationales similar to those for longevity and ageing apply to developmental stabilities. In mitochondria, the chemical stability of rRNA increases developmental stability (Seligmann, 2006a), and the structural stability of the regular light strand origin of replication (OL) also increases developmental stability. So does usage of tRNAs adjacent to the regular OL as additional OLs (Seligmann and Krishnan 2006). Densities of off frame stops in mitochondrial genomes also increase developmental stability, probably because off frame stops stop early translation after unprogrammed ribosomal frameshifts, which produce dysfunctional proteins (Seligmann, 2010a). It hence makes sense to expect that connections between mitochondrial transcription and replication could affect developmental stability as well as lifespan.

\subsection{Mutation gradients across genomes}

Deamination gradients exist along mitochondrial genomes proportionally to $D_{\text {ssh }}$ during replication $\left(\mathrm{D}_{\mathrm{ssh}} \mathrm{r}\right)$. In several independent taxa, inversion of the mitochondrial control region inverts the directions of these gradients (Hassanin et al., 2005).

$\mathrm{D}_{\text {ssh }}$ during transcription $\left(\mathrm{D}_{\text {ssh }} \mathrm{t}\right)$ also creates deamination gradients along genomes or sections of genomes. The relative dominance of replication- versus transcription-associated gradients varies among genome regions and organisms (Francino et al., 1996; Baran et al., 2003), especially in bacteria (Mackiewicz et al., 1999). It seems that in nuclear vertebrate genomes, transcription-associated gradients mask the replication-associated ones (Hou et al., 2006), and more complex analyses are required to detect them (Touchon et al., 2005). These nuclear vertebrate transcription-associated gradients even reveal genes that are otherwise undetected because of their long introns and low sequence conservation (Glusman et al., 2006). Replication-associated deamination gradients are usually present in bacteria (Mrazek \& Karlin, 1998). Transcription-associated ones have also been detected in bacteria (Francino \& Ochman, 2001). In an adenovirus, gradients in nucleotide composition asymmetries between strands exist where replication and transcription share directions, but are basically nonexistent where they have opposite directions (Grigoriev, 1999).

In the latter case, this lack of a clear gradient does not signify that no mutations occur during replication and transcription, but rather that maximal and minimal mutation rates of each process coexist in the same region, increasing the range of the genome that is affected by high mutation regimes from at least one of the two processes. This might be adaptive in viruses, by maximizing evolvability (see for example Aldana et al., 2007; Feder, 2007; Jones et al., 2007). But, it is no surprise that both processes are frequently collinear in other organisms, as this limits maximal mutation rates to a specific region that might have relatively high mutational robustness, decreasing mutational constraints on the rest of the genome (Ciliberti et al., 2007; Elena et al., 2007; Wagner \& Wright, 2007). It also makes sense that replication and transcription gradients, reflecting the relative frequencies of each process, are approximately balanced in prokaryotes. Hence the tendency for dominance of transcription-related gradients in nuclear genomes of eukaryotes would result from their generally lower cell replication rates. According to this, their mitochondria should resemble bacteria.

\subsection{Convergence of replication and transcription in mitochondria}

The level of collinearity, also termed here convergence, between replication and transcription is expected to slow ageing and ageing-related processes. Vertebrate 
mitochondrial genomes seem good candidates for testing this hypothesis, because a) data are available for many species, b) they affect ageing and c) mitochondrial replication and transcription are at least partially collinear.

Indeed, in vertebrate mitochondria, the distance from the D-loop determines $\mathrm{D}_{\text {ssh }} \mathrm{t}$, while $\mathrm{D}_{\mathrm{ssh}} \mathrm{r}$ results from calculating relative distances from the $\mathrm{OH}$, also in the D-loop, and the light strand replication origin (OL, see Seligmann et al., 2006b for details on $\mathrm{D}_{\text {ssh }}$ calculations, and Seligmann, 2008). Usually, one considers that mitochondrial genomes have a single OL located in the WANCY region, a cluster of 5 tRNA genes (Desjardins \& Morais, 1990; Clayton, 2000), resulting in $\mathrm{D}_{\mathrm{ssh}} \mathrm{rW}$. Both processes are only partially collinear when solely the WANCY region functions as OL, but the probabilistic combination of multiple tRNA clusters distributed across the genome that putatively act as OLs (Seligmann et al., 2006b; Seligmann, 2008; Seligmann, 2010b) can result in an overall replication gradient $\left(D_{\text {ssh }} \mathrm{rX}\right)$ collinear with the transcription gradient $\left(\mathrm{D}_{\mathrm{ssh}} \mathrm{t}\right)$. In Figure $1, \mathrm{D}_{\mathrm{ssh}} \mathrm{rX}$ (as it is expected after integrating with equal weights all putative tRNA clusters as OLs into $D_{\text {ssh }} \mathrm{r}$ calculations) is highly correlated with the distance from the Dloop. As compared to $\mathrm{D}_{\mathrm{ssh}} \mathrm{rW}$, this $\mathrm{D}_{\text {ssh }} \mathrm{r} X$ has only one region with high mutation risks (this region codes for ND6 and $\mathrm{CytB}$ ), while for $\mathrm{D}_{\mathrm{ssh}} \mathrm{rW}$, there is an additional region (coding for ND1 and ND2), ranging

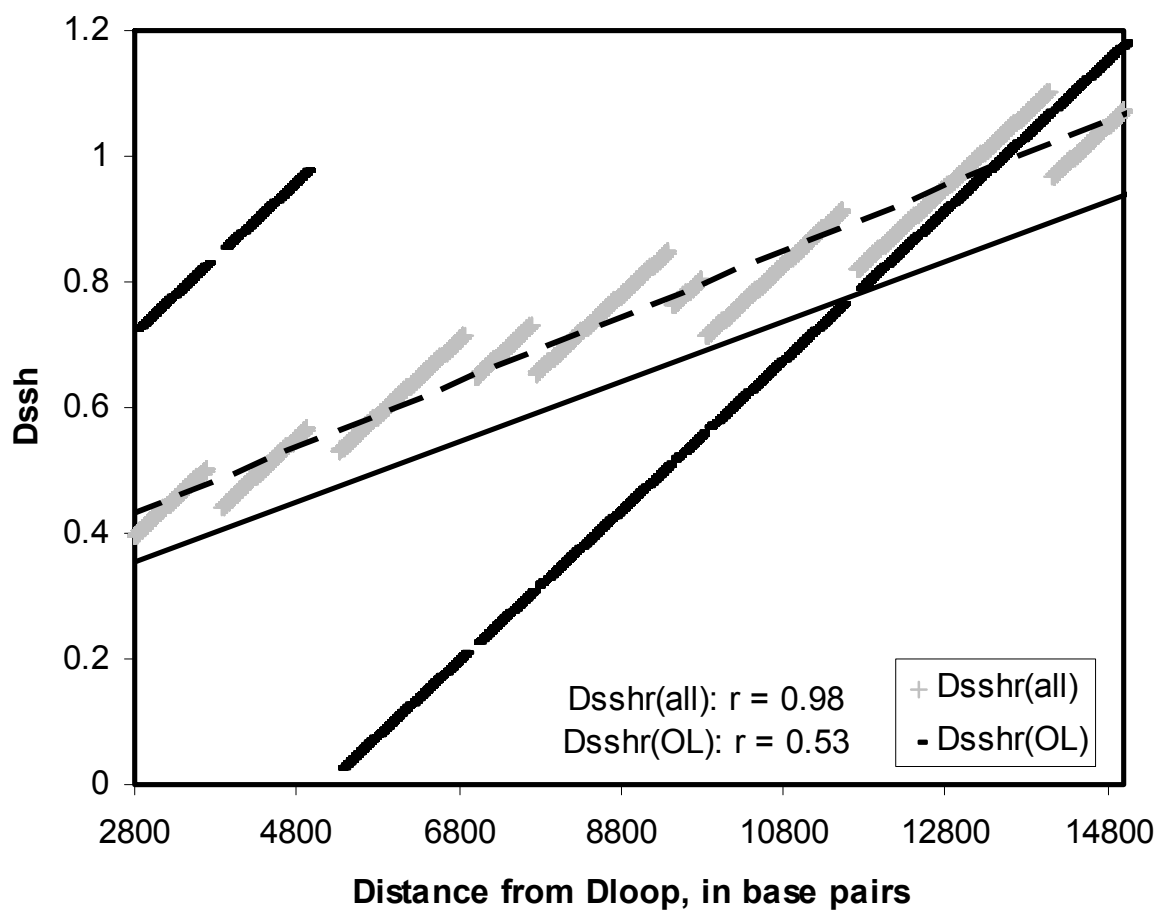

Fig. 1. Duration of time spent single stranded during replication $\left(D_{s s h} r\right)$ as a function of distance in number of base pairs from the heavy strand promoter in the mitochondrial Dloop. Black- $\mathrm{D}_{\mathrm{ssh}} \mathrm{r}$ assuming a single light strand origin of replication, OL, in the WANCY region, termed $\mathrm{D}_{\text {ssh }} \mathrm{rW}$ in the text; grey- $\mathrm{D}_{\mathrm{ssh}} \mathrm{rX}$, assuming that all DNA regions coding for tRNAs function at equal weights as additional OLs. 
over 4 of all 13 mitochondrially encoded protein coding genes and both rRNAs. Hence, one could expect that evolution of multiple OLs in mitochondrial genomes, especially in taxa with long lifespan, would tend towards increasing collinearity of $\mathrm{D}_{\text {ssh }} \mathrm{rX}$ with $\mathrm{D}_{\text {ssh }} \mathrm{t}$, reducing the extent of DNA regions with high mutation risks. Multiple OLs would regulate $\mathrm{D}_{\text {ssh }} \mathrm{r}$ $>\mathrm{D}_{\text {ssh }}$ convergence. These interactions between mitochondrial replication and transcription would be an additional process interacting with mitochondrial transcription (Bonawitz et al., 2006).

\subsection{Alternative replication mechanisms}

This is in line with studies suggesting that multiple OLs exist in vertebrate mitochondria (Brown et al., 2005; Brown \& Clayton 2006; Clayton \& Brown 2006). The hypothesis that mitochondrial light strands are replicated at multiple locations by Okazaki fragments (Holt et al., 2000) as the lagged strand in nuclear genomes is also compatible with the statistical patterns observed by Seligmann et al., (2006b). In fact, the deamination gradients detected by comparative analyses are considered as strong evidence in favor of the unidirectional replication mechanisms (Gibson, 2005). My interpretation is that the unidirectional replication is relatively rare, but it leaves at evolutionary scales a clear imprint on genomes because it causes biases in mutation patterns, and that at least one other replication process, putatively similar to the one in nuclei, exists. That process is more frequent and effective, affecting less the genome at evolutionary scale. Indeed, some evidence on mitochondrial transcription factors suggests that two replication modes coexist, and that the modes of mitochondrial replication are regulated by mitochondrial metabolism (Pohjoismaki et al., 2006). Results and conclusions will be also interpreted according to this hypothesis, considering that only one replication mechanism, the unidirectional one, creates replication deamination gradients.

\subsection{Lifespan and convergence of replication and transcription}

Heavy strand sequences of mitochondrial tRNA genes tend to form OL-like structures and seem to assist the "recognized" vertebrate mitochondrial OL in the WANCY region (Seligmann \& Krishnan, 2006). $\mathrm{D}_{\text {ssh }} \mathrm{r} X$ resembles $\mathrm{D}_{\text {ssh }} \mathrm{t}$ more than does $\mathrm{D}_{\text {ssh }} \mathrm{rW}$ (see Figure 1, and Seligmann et al., 2006b). Pathogenic mutations, as compared to non-pathogenic polymorphisms in human mitochondrial tRNAs, disturb the fine balance of $\mathrm{D}_{\text {ssh }} \mathrm{rX}$ by altering which tRNAs function and which do not function as alternative OLs (Seligmann et al., 2006b). These observations strengthen the hypothesis that collinearity between these processes increases longevity by slowing ageing.

A further observation in line with this hypothesis is that nucleotide contents of heavy strand DNA sequences coding for the first and second positions of tRNA anticodons in vertebrate mitochondrial genomes correlate with $\mathrm{D}_{\text {ssh }} \mathrm{t}$ calculated according to the highly conserved tRNA arrangement along the vertebrate mitochondrial genome. When mitochondrial replication and transcription are collinear, as observed in Homo sapiens after integrating all putative OLs in $\mathrm{D}_{\mathrm{ssh}} \mathrm{rX}$ calculations, overall deamination risks at sites coding for the first two anticodon positions are minimized (Seligmann et al., 2006b), not only during transcription, but also during replication because replication is collinear with transcription in this case. It hence makes sense that ageing-related processes, such as developmental stability and lifespan, are affected by convergence between replication and transcription. I test this hypothesis and discuss alternative hypotheses that could account for the patterns described below. 


\section{Materials and methods}

In order to test this ageing-related collinearity hypothesis, I calculated rt, the correlation coefficient between $\mathrm{C}$ or $\mathrm{T}$ contents at third codon positions for all 13 protein coding genes (methodology as in Seligmann et al., 2006b) and $\mathrm{D}_{\text {ssh }} \mathrm{t}$; and $\mathrm{rW}$, the correlation coefficient between $\mathrm{C}$ or $\mathrm{T}$ contents as above, and $\mathrm{D}_{\text {ssh }} \mathrm{rW}$. I used the light strand sequences, coding Cs by "1" and Ts by zero, so that the gradient reflects the slower deamination reaction of A to G that occurs during replication on the heavy strand as a function of $\mathrm{D}_{\text {ssh. }}$. did also similar calculations for the other gradient, coding light strand As by "1" and Gs by zero, reflecting the heavy strand gradient due to the faster deamination of $C$ to $T$. Results were generally qualitatively similar for this gradient, but are not presented here.

I used for $\mathrm{D}_{\text {ssh }}$ calculations the numbering system of Genbank for nucleotide sites, also used by Tanaka and Ozawa (1994) and Seligmann et al., (2006b). $\mathrm{D}_{\text {ssh }}$ t is the relative distance of the base pair from the starting point of the transcription, meaning the number assigned to that base pair following that numbering system divided by the total length of the genome:

$$
\mathrm{D}_{\mathrm{ssh}} \mathrm{t}=\mathrm{b} / \mathrm{N} \text {, }
$$

where $\mathrm{b}$ is the distance in bases of the nucleotide position from the genome numbering starting point and $\mathrm{N}$ is the total mitochondrial genome length.

I calculated $\mathrm{D}_{\mathrm{ssh}} \mathrm{rW}$ of ND1 and ND2 genes using the equation:

$$
\mathrm{D}_{\mathrm{ssh}} \mathrm{rW}=\left((\mathrm{N}-\mathrm{W})^{\star} 2+\mathrm{b}-(\mathrm{N}-\mathrm{b})\right) / \mathrm{N},
$$

where $\mathrm{W}$ is the position at mid-location of the sequence forming the classical light strand replication origin. In species lacking the classical origin, I used for $\mathrm{W}$ the mid-location of the sequence located between the two tRNAs that normally flank the regular light strand replication origin, tRNA-Asn and tRNA-Cys. For other genes, I calculated $\mathrm{D}_{\text {ssh }} \mathrm{rW}$ according to the equation:

$$
\mathrm{D}_{\mathrm{ssh}} \mathrm{rW}=(\mathrm{b}-\mathrm{W}) * 2 / \mathrm{N} .
$$

Note that visual examinations of gradients in single species, such as those shown in Figure 2 , are based on gene-wise averages of the binary $\mathrm{C}$ and $\mathrm{T}$ contents of that gene at third codon position. Analyses based on such averages would probably yield qualitatively similar results. I opt for the method using site specific nucleotide contents, without averaging over genes in order to maximize the amount of information used from the raw sequence data. It is possible that reducing data by averaging following the natural units of protein coding sequences might reveal additional phenomena or aspects of the main phenomenon examined, a point that should be kept in mind. The gene-wise averaging method has clear advantages for graphical presentation and is therefore used here in various Figures.

$\mathrm{D}_{\text {ssh }} \mathrm{r}$ calculations for tRNA clusters different from the WANCY region containing the classical light strand replication origin are done following Seligmann et al., (2006b). These calculations were not used besides for Figure 1, for other analyses presented here, only $\mathrm{D}_{\mathrm{ssh}} \mathrm{rW}$ and $\mathrm{D}_{\text {ssh }} \mathrm{rt}$ were used. $\mathrm{D}_{\mathrm{ssh}} \mathrm{r}$ calculations for the various tRNA clusters as light strand replication origins, as they were used to estimate $D_{s s h} r X$ in Figure 1, are calculated following the principles described by Seligmann (2008).

This was done for a number of mammalian and reptilian taxa, notably for 26 complete Primate mitochondria, and two outgroups, Cynocephalus variegatus and Tupaia belangeri. The 
correlation coefficients, $\mathrm{rt}$ and $\mathrm{rW}$ are used here as estimates of gradient strengths. In Primates, I tested for correlations of $\mathrm{rt}$ and $\mathrm{rW}$ each, with the maximal lifespan of these taxa (lifespan data from http://genomics.senescence.info/species/ (de Magalhaes \& Costa, 2009), besides for Chlorocebus sabaeus (Sade and Hildrech 1965), Procolobus badius (http://www.missouri.edu/ anthmark/courses/mah/factfiles/redcolubus.htm) and Pongo abelii (Wich et al., 2004)). In other groups, I only tested for the correlation of rt-rW with lifespan. The use of maximal lifespan for animals in captivity is a reasonable proxy for longevity, as well as maximal lifespan in the wild, as was shown at least in geckos (Werner et al., 1993). Before using correlation coefficients as variables in analyses, they were $\mathrm{z}$ transformed in order to linearize their scales (Amzallag, 2001) considering sample sizes (Seligmann et al., 2007). Analyses were done for various groups for which the relevant genomic and life history data were available for a sufficient number of species. For lizards, correlations with lifespan were tested, as well as correlations with estimates of developmental stabilities, when such were available (Seligmann et al., 2003). Two independent sets of lizard species were used: Amphisbaenidae, (Bipes biporus, Bipes canaliculatus, Bipes tridactylus, Diplometopon zarudnyi, Rhineura floridana), using the number of intercalated annuli on the ventral side of these animals (Seligmann \& Krishnan, 2006) as a measure of developmental instability (the association with maximal longevity was not tested in this group because of lack of longevity data), and species for which both complete genome sequences and estimates of maximal lifespan* or fluctuating asymmetry $\$$ in subdigital lamellae under the fourth toe were available (Agamidae, Calotes versicolor $\$$; Anguidae, Abronia graminea\$; Cordylidae, Cordylus warreni*; Eublepharidae, Coleonyx variegatus*\$; Gekkonidae, Gekko gecko*\$, Gekko vitattus\$; Helodermatidae, Heloderma suspectum*; Iguanidae, Iguana iguana*; Lacertidae, Lacerta viridis*\$, Takydromus tachydromoides\$; Scincidae, Eumeces egregius\$; Sceloporidae, Sceloporus occidentalis\$; Xantusiidae, Lepidophyma flavimaculatum*\$). $\mathrm{D}_{\text {ssh }}$ calculations for species possessing duplicate Dloops are not straightforward and deserve special treatment. Such species (i.e. Varanus niloticus, Sphenodon punctatus) were excluded from analyses.

I also tested for correlations of rt-rW, termed collinearity between gradients or $D_{s s h} r->D_{s s h} t$ convergence, with the length of the gestation period. Information on gestation periods is also from http://genomics.senescence.info/species/.

\section{Results and discussion}

\subsection{Replication versus transcription gradients in various species}

Examining graphs plotting the mean $\mathrm{C} / \mathrm{T}$ ratio at third codon position for each gene as a function of $\mathrm{D}_{\text {ssh }} \mathrm{t}$ and as a function of $\mathrm{D}_{\text {ssh }} \mathrm{rW}$, one finds that for a majority of species, $\mathrm{D}_{\text {ssh }} \mathrm{rW}$ is the better predictor of nucleotide contents at third codon positions and there is no evidence for a gradient resembling the one that would be expected due to transcription, whether due to replication convergent with transcription or transcription itself (for example the greater white-toed shrew Crocidura russula in Figure 2a). In some species, usually relatively long lived, such as in the western gorilla and the Yangtze river dolphin Lipotes vexillifer (Figures $2 b, c$ ), the situation is less clear, with both $\mathrm{D}_{\text {ssh }} \mathrm{t}$ and $\mathrm{D}_{\mathrm{ssh}} \mathrm{rW}$ explaining a significant amount of variation in nucleotide contents, although $\mathrm{D}_{\mathrm{ssh}} \mathrm{rW}$ is the better predictor and hence can be considered as the major cause of the gradient (meaning, the WANCY region would be the most commonly used OL). In some rarer cases, such as in the yellow-spotted night lizard Lepidophyma flavimaculatum (Figure 2d), the correlation 

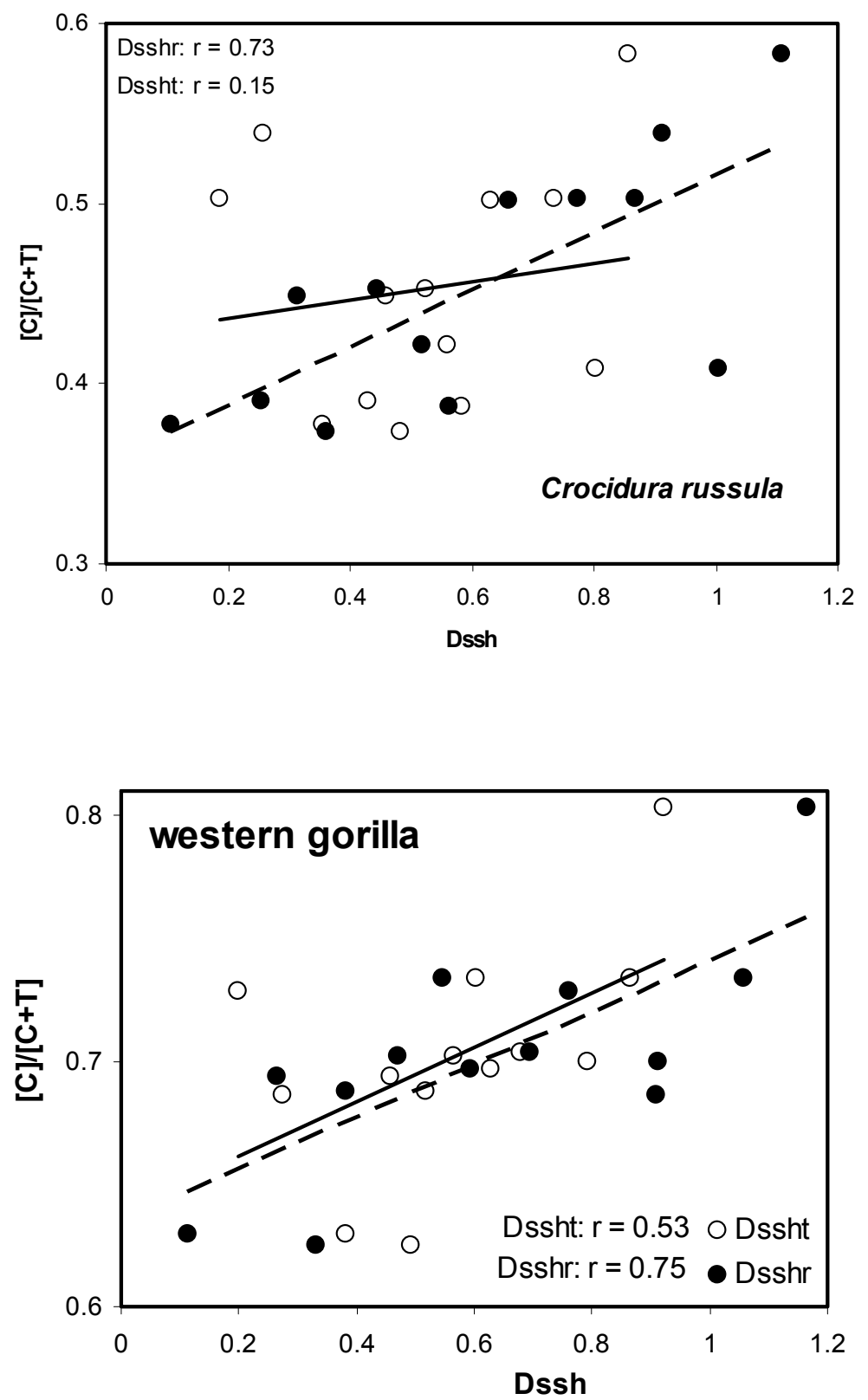

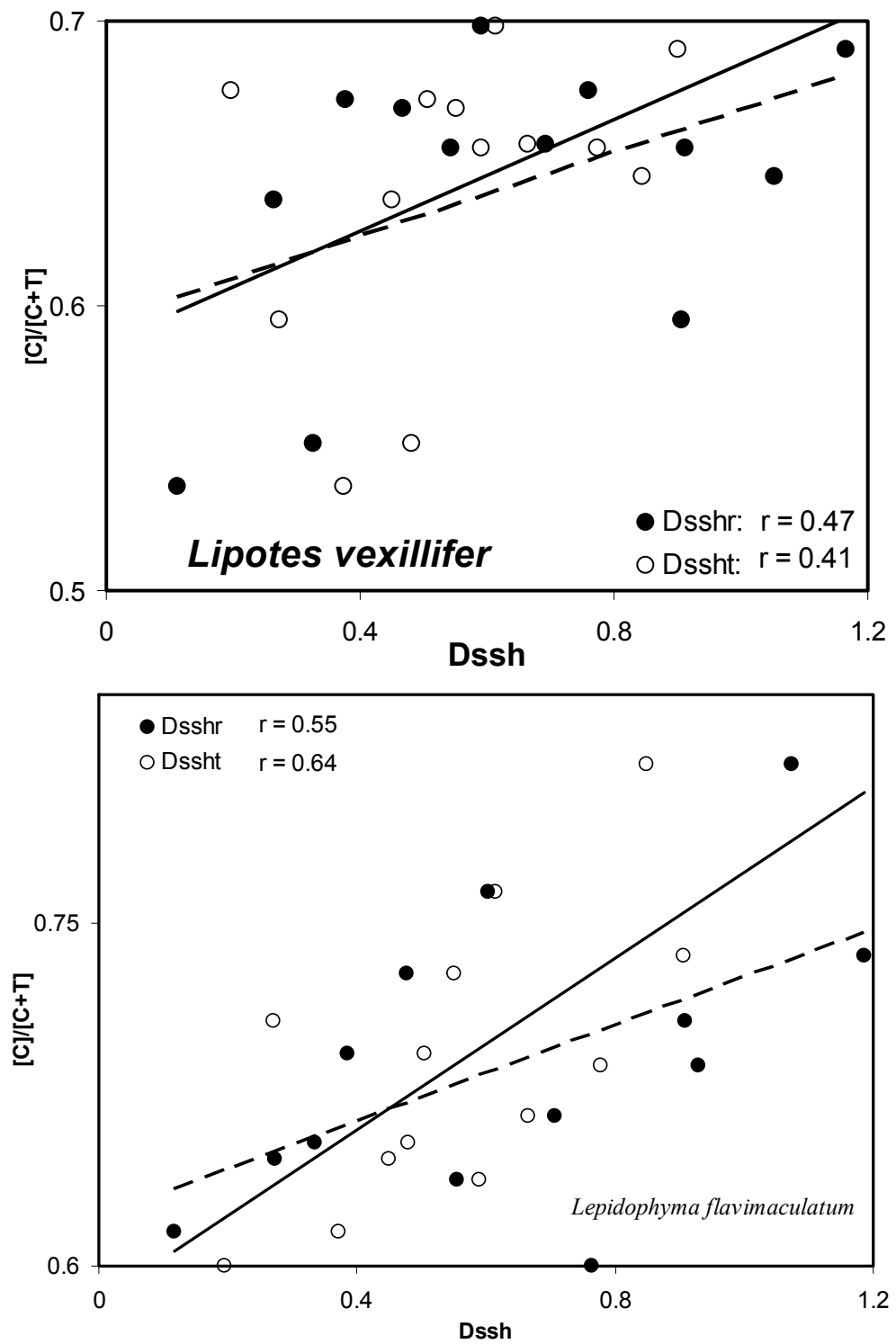

Fig. 2. Proportion of cytosine at third codon positions as a function of time spent single stranded during transcription $\left(D_{\text {ssh }} t\right)$ and replication $\left(D_{\text {ssh }} \mathrm{r}\right)$ in 13 mitochondrial protein coding sequences: a) in the insectivore Crocidura russula, a typical example where the replication gradient is by far stronger than the transcription-like gradient; $b$ ) in the western gorilla, where the transcription-like gradient is apparent, but weaker than the replication gradient; c) in the cetacean Lipotes vexillifer, where both gradients are similar; and d) in the lizard Lepidophyma flavimaculatum, where the transcription-like gradient is stronger than the replication one. 
of nucleotide contents with $\mathrm{D}_{\text {ssh }}$ is better than with $\mathrm{D}_{\mathrm{ssh}} \mathrm{rW}$, indicating that in that species, processes causing deamination gradients due to the time spent single stranded tend to start usually within the Dloop. This could either indicate that in that species the frequency of transcriptions is overwhelmingly larger than of replications, or that replication does relatively rarely start in the region of the regular OL. The latter option is in line with the fact that there is no recognized OL sequence in that lizard species at the regular OL location, between tRNA-Asn and tRNA-Cys, and that in this species, unlike in other lizards lacking a recognized OL sequence between these tRNAs, the adjacent $5^{\prime}$ arm of tRNA-Asn and $3^{\prime}$ arm of tRNA-Cys, including the short intergenic sequence, do not form OL-like structures as those found in Trogonophis (Seligmann \& Krishnan, 2006) and other lizards (Macey et al., 1997). Hence it is likely that patterns are due to replication resembling (converging with) transcription, rather than due to transcription itself. This point is further discussed below.

These observations suggest that variation exists among species in the extent that $D_{\text {ssh }} r$ converges with $\mathrm{D}_{\text {ssh }} \mathrm{t}$, and that this variation might associate with life history: in the examples presented, regular replication gradients starting at the recognized OL sequence are observed in short lived species with high metabolic rates (shrew), while the convergence between replication and transcription increases for more long lived species with lower metabolisms (gorilla, dolphin, lizard), paralleling the dichotomy noted above for gradients between prokaryotes (where patterns remind more those found in mitochondria of short lived mammals) and eukaryotes (resembling more those found in mitochondria of long lived animals with slower metabolisms). This justifies testing whether the extent of $\mathrm{D}_{\text {ssh }} \mathrm{r}-$ $>\mathrm{D}_{\text {ssh }} \mathrm{t}$ convergence correlates with lifespan and other ageing-related processes.

\subsection{Gradient convergence and lifespan in Primates}

In Primates, the strength of the replication gradient that considers only the recognized OL $(\mathrm{rW})$ does not correlate with maximal lifespan $(\mathrm{r}=0.11, \mathrm{P}=0.29$, one tailed test, not shown); the strength of the transcription gradient $(\mathrm{rt})$ increases with maximal lifespan $(\mathrm{r}=0.318, \mathrm{P}=$ 0.049 , one tailed test, not shown). This improvement in the correlation with lifespan fits the prediction that the actual replication gradient, calculated having considered all putative OLs and not only the one in the WANCY region, is to some extent collinear with the transcription gradient, and hence the strength of the transcription gradient, $\mathrm{rt}$, is a better estimate of the strength of the replication gradient than $\mathrm{rW}$. In this case, and as expected by the working hypothesis, the extent by which rt is stronger than $\mathrm{rW}$ would measure the extent by which $\mathrm{D}_{\text {ssh }} \mathrm{rX}$ resembles $\mathrm{D}_{\text {ssh }}$.

I quantified this extent by calculating the residuals of $\mathrm{rt}$ for each Primate species from the regression between $\mathrm{rt}$ (dependent) and $\mathrm{rW}$ (independent) $\left(\mathrm{rt}=0.822^{*} \mathrm{rW}+0.04, \mathrm{r}=0.83, \mathrm{P}<\right.$ 0.001). These residuals are unlikely, from a statistical point of view, to correlate with lifespan because rt correlates with lifespan: they represent only a small fraction of the variation inherent to rt because $\mathrm{rW}$ explains $69 \%$ of the variation in rt. Nevertheless, results show that they correlate better than $\mathrm{rt}$ with maximal lifespan $(\mathrm{r}=0.405, \mathrm{P}=0.016,1$ tailed test; see Figure 3), indicating that the extent of $D_{\text {ssh }} r->D_{\text {ssh }}$ convergence affects lifespan. Analyses reveal similar patterns in other groups, such as Carnivora (Figure 4, analyses excluding Pinnipedia). In these cases, no residual analyses were done, and rW was simply subtracted from rt. The correlation is positive as expected for a pool of groups excluding Mustelidae and other closely related groups. Patterns in Mustelidae closely resemble those for other Carnivora, besides for an outlier, the Eastern spotted skunk (Spilogale putorius), whose maximal lifespan is lower than expected considering its relatively high $D_{\text {ssh }} r->D_{\text {ssh }} t$ convergence. 


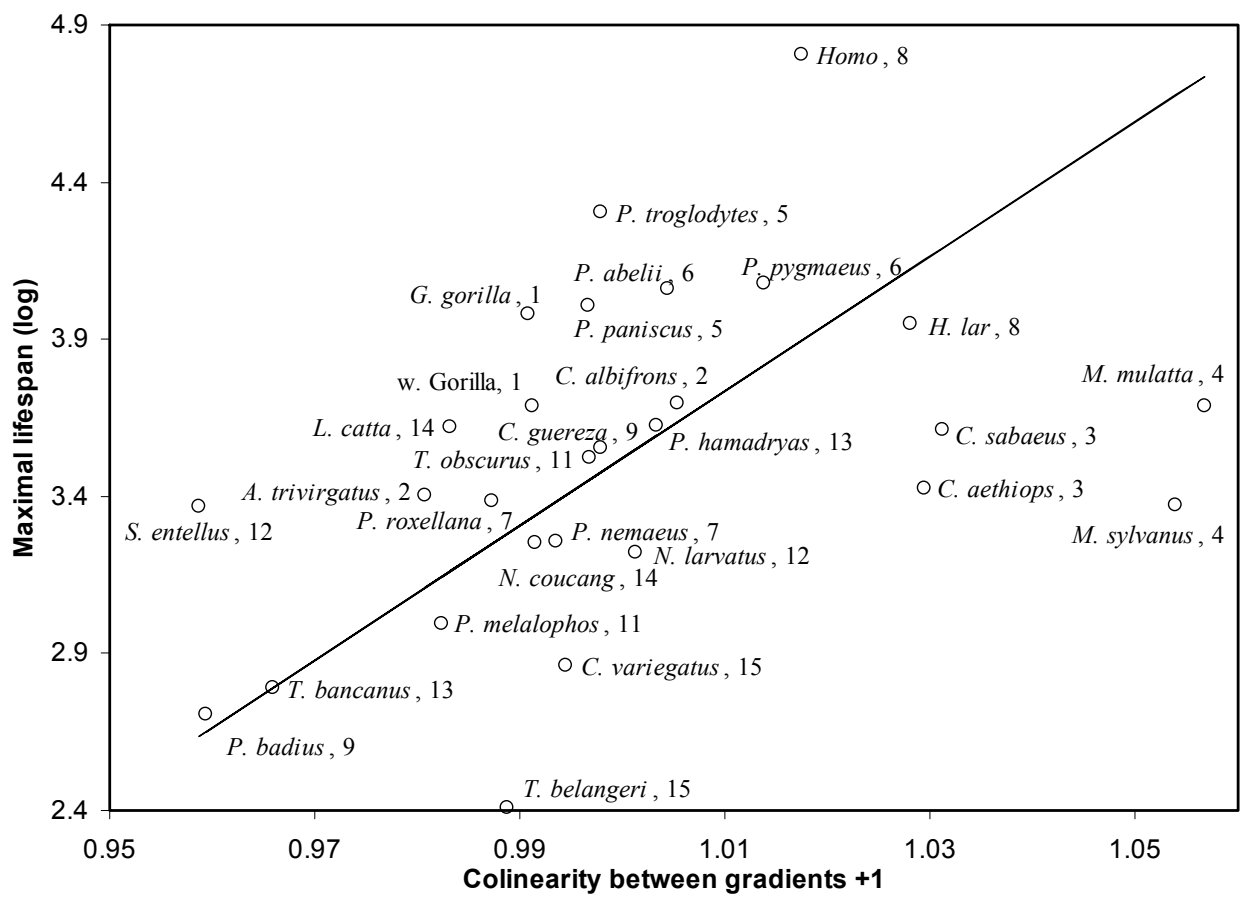

Fig. 3. Maximal primate lifespan as a function of a measure of convergence between replication and transcription in primate mitochondrial genomes. The $x$ axis is the residual of $\mathrm{rt}$, the strength of the transcriptional deamination gradient, with $\mathrm{rW}$, the strength of the replicative deamination gradient calculated considering only the classically recognized OL in the WANCY region. Gradient strengths are estimated by Pearson correlation coefficients (see also text for further explanations). Species names are followed by numbers that indicate pairing in phylogenetic contrast analyses, then by NCBI (genbank) entries for species that were not used by Seligmann et al. 2006a: Aotus trivirgatus2; Cebus albifrons2; Chlorocebus aethiops ${ }^{3}$; Chlorocebus sabaeus ${ }^{3}$, NC_008066; Colobus guereza9; Cynocephalus variegatus ${ }^{15}$, NC_004031; Gorilla gorilla1; western Gorilla1; Homo sapiens ${ }^{8}$; Hylobates lar8; Lemur catta14; Macaca mulatta4; Macaca sylvanus4; Nasalis larvatus ${ }^{12}$, NC_008216; Nycticebus coucang14; Pan paniscus ${ }^{5}$; Pan troglodytes ${ }^{5}$; Papio hamadryas ${ }^{13}$; Pongo abelii6; Pongo pygmaeus 6 ; Presbytis melalophos ${ }^{11}$, NC_008217; Procolobus badius ${ }^{9}$; Pygathrix nemaeus ${ }^{7}$, NC_008220; Pygathrix roxellana ${ }^{7}$, NC_008218; Semnopithecus entellus ${ }^{12}$, NC_008215; Tarsius bancanus ${ }^{13}$; Trachypithecus obscurus ${ }^{11}$; Tupaia belangeri15, NC_002521. 


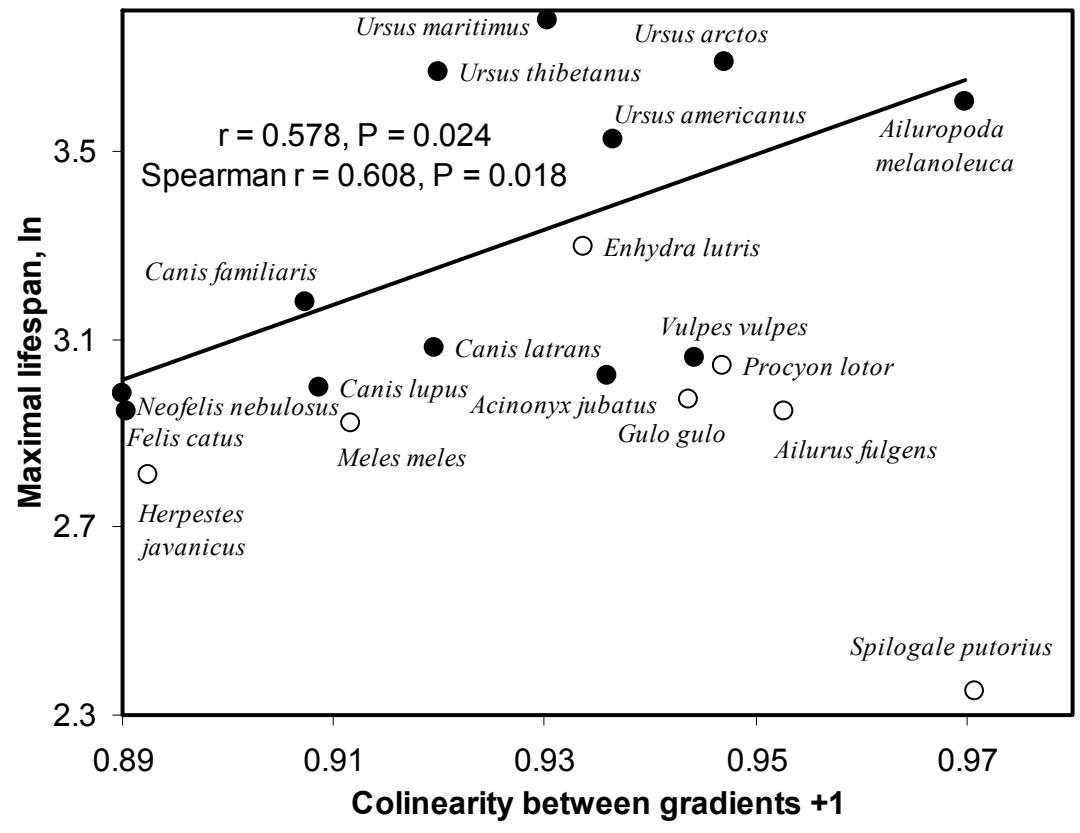

Fig. 4. Maximal lifespan as a function of a measure of convergence between replication and transcription in mitochondrial genomes of two groups of Carnivora, excluding Pinnipedia. The $\mathrm{x}$ axis is the subtraction of $\mathrm{rW}$, which estimates the strength of the regular replication gradient, from rt, which estimates the strength of the transcription-like gradient. Species names are followed by NCBI (genbank) entries. Full symbols are for Carnivora excluding Mustelidae and consorts: Acinonyx jubatus, NC_005212; Ailuropoda melanoleuca, NC_009492; Canis familiaris, NC_002008; Canis latrans, NC_008450; Canis lupus, NC_008066; Felis catus, NC_008450; Neofelis nebulosus, NC_008450; Ursus arctos, NC_003427; Ursus americanus, NC_003426; Ursus maritimus, NC_003428; Ursus thibetanus, NC_009431; Vulpes vulpes, NC_008434. Open symbols are for Mustelidae and consorts: Ailurus fulgens, NC_009691; Enhydra lutris, NC_009692; Gulo gulo, AM711901; Herpestes javanicus, NC_004031; Meles meles,NC_009677; Procyon lotor, NC_009126; Spilogale putorius, AM711988. Correlation analyses exclude Mustelidae.

\subsection{Convergence of replication towards transcription}

Analyses between the various life history traits and gradient strengths presented and discussed in the rest of this study did not detect any significant correlation with $\mathrm{rW}$, while those with rt were systematically stronger and sometimes statistically significant. This is despite the strong mathematically trivial correlation existing between $\mathrm{rt}$ and $\mathrm{rW}$, which is also apparent from Figure 1. But the strongest correlations were systematically with rt-rW, confirming that the factor that is most relevant to life history is the extent of convergence of replication towards transcription, rather than the extent of the transcription-like replication gradient. This is the main point of the hypothesis presented here. 


\subsection{Too extreme convergence between replication and transcription decreases lifespan}

Closer examinations of Figures 3 and 4 reveal that for species with relatively high (or even extreme) convergence between gradients (rt>rW: Cercopithecus aethiops, C. sabaeus, Macaca mulatta and M. sylvanus in Primates; Figure 3; similar patterns exist in Mustelidae, Figure 4), lifespan is sometimes much below the general trend expected according to other species with lower convergence levels.

This suggests that at high $\mathrm{D}_{\text {ssh }} \mathrm{r}->\mathrm{D}_{\text {ssh }}$ convergence levels, another factor decreases lifespan. It is plausible that collinearity between the processes increases the frequency of collisions between replication and transcription forks. This decreases the respective rates of these processes, increasing the overall time spent single stranded, causing more mutations. This increase might be greater than the relative decrease in mutation rate due to collinearity between the processes, especially at high collinearity levels. Figure 5 plots lifespan in

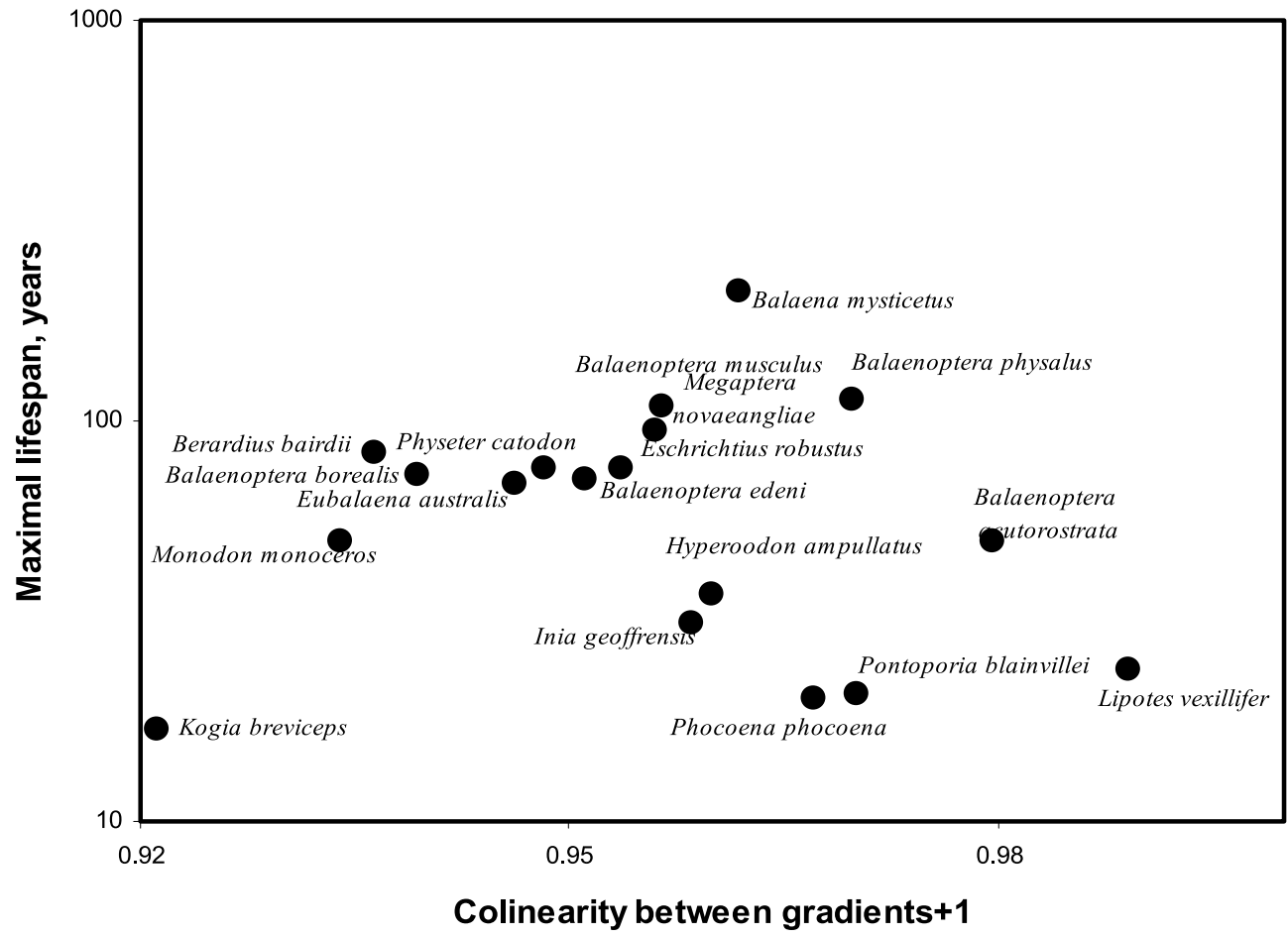

Fig. 5. Maximal lifespan as a function of a measure of convergence between replication and transcription in mitochondrial genomes in Cetacea. Axes are as in Figure 3. Species names are followed by NCBI (genbank) entries: Balaena mysticetus, NC_005268; Balaenoptera acutorostrata, NC_005271; Balaenoptera borealis, NC_006929; Balaenoptera edeni, NC_007938; Balaenoptera musculus, NC_001601; Balaenoptera physalus, NC_001321 ; Balaenoptera bairdii, NC_005274; Eschrichtius robustus, NC_005279; Eubalaena australis, NC_006930; Hyperoodon ampullatus, NC_005273; Inia geoffrensis, NC_005276; Kogia breviceps, NC_005272; Lipotes vexillifer, NC_007629; Megaptera novaeangliae, NC_006927; Monodon monoceros, NC_005279; Phocoena phocoena, NC_005280; Physeter catodon, NC_002503; Pontoporia blainvillei, NC_005277. 
Cetacea as a function of $D_{\text {ssh }} \mathrm{r}->\mathrm{D}_{\text {ssh }} \mathrm{t}$ convergence. At low convergence levels, lifespan increases with convergence until a threshold region in $\mathrm{D}_{\mathrm{ssh}} \mathrm{r}->\mathrm{D}_{\text {ssh }} \mathrm{t}$ convergence. Beyond that threshold, lifespan decreases with $D_{s s h} r->D_{\text {ssh }} t$ convergence. It is hence not a surprise to find a negative correlation between $D_{\text {ssh }} r->D_{\text {ssh }}$ convergence and maximal lifespans in lizards (Figure 6). Hence the few outliers found in Figures 3 and $4 a$ would reflect the same phenomenon as the one observed for a larger part of species in Cetacea (those for which a negative correlation of lifespan with convergence for high convergence levels exists) or for lizards (Figure 6).

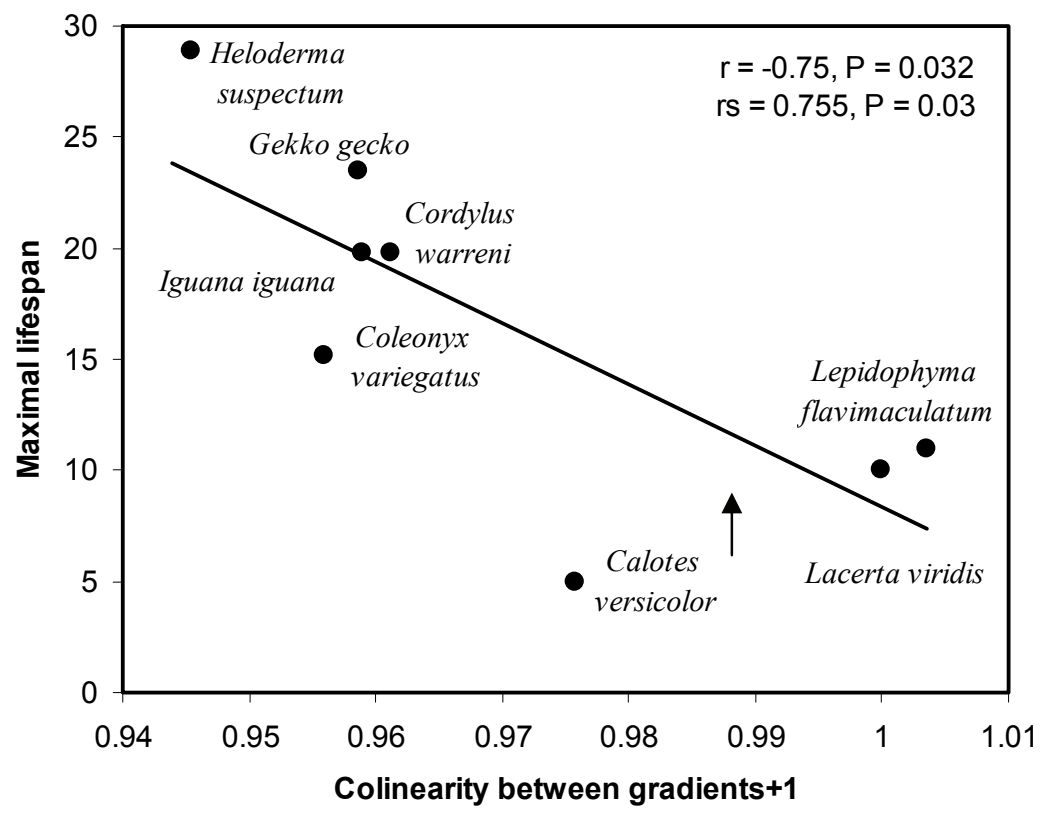

Fig. 6. Maximal lifespan as a function of a measure of convergence between replication and transcription in lizard mitochondrial genomes possessing only one Dloop region. Axes are as in Figure 4. Species names are followed by NCBI (genbank) entries: Calotes versicolor (NC_009683), Coleonyx variegatus (NC_008774), Cordylus warreni (NC_005962), Gekko gecko (NC_007627), Heloderma suspectum (NC_008776), Iguana iguana (NC_002793), Lacerta viridis (NC_008328) and Lepidophyma flavimaculatum (NC_008775).

\subsection{Developmental stability and convergence between transcription and replication} Analyses testing for correlations between $D_{\text {ssh }} r->D_{\text {ssh }}$ convergence and developmental stabilities yield qualitatively similar results to those found for associations with maximal lifespan: in some groups, convergence decreases stability (in a pool of lizards from several families, $r=-0.52$, Figure 7), and in others, convergence decreases instability (Amphisbaenia, $r=-0.76$, Figure 8 ).

\subsection{Rates of development and convergence between replication and transcription}

As noted above, convergence between replication and transcription increases the frequency of collisions between these processes, hence decreasing their respective rates. Ultimately, 
decreased replication and transcription rates should impede on an organism's development, decreasing its differentiation and growth rates. I used the length of the gestation period as an estimate inversely proportional to differentiation rate and tested for the expected positive correlation between gestation period and $D_{s s h} r->D_{s s h} t$ convergence levels (see the example for Insectivora in Figure 9). Because maximal lifespan, together with brain size, correlates positively with the length of the gestation period (Sacher \& Staffeld, 1974; Jones \& MacLarnon, 2004), this result does not independently confirm the $D_{s s h} r->D_{\text {ssh }} t$ convergence hypothesis, despite that the mechanisms assumed to cause the correlations with lifespan and those with gestation length differ: lifespan is presumed to increase because convergence increases mutational robustness (only extreme convergence decreases mutational robustness and lifespan); at the same time, convergence decreases the rates of replication and transcription,, and presumably also developmental rates.

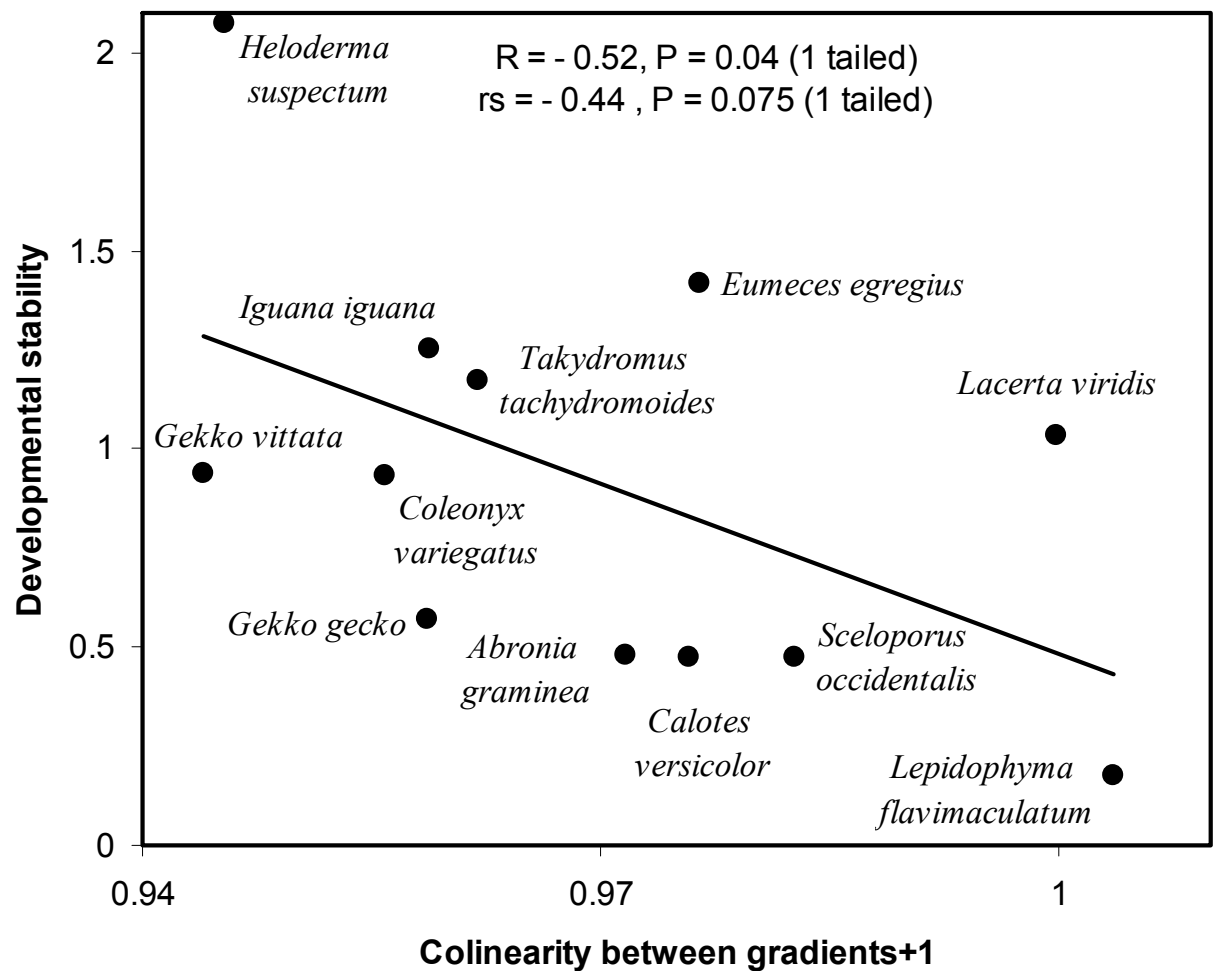

Fig. 7. Developmental stability in subdigital lamellae counts as a function of a measure of convergence between replication and transcription in lizard mitochondrial genomes possessing only one Dloop region. $\mathrm{X}$ axis is as in Figure 4 . Species names are followed by NCBI (genbank) entries: Abronia graminea (NC_005958), Calotes versicolor (NC_009683), Coleonyx variegatus (NC_008774), Eumeces egregius (NC_000888), Gekko gecko (NC_007627), Gekko vittatus (NC_008772), Heloderma suspectum (NC_008776), Iguana iguana (NC_002793), Lacerta viridis (NC_008328), Lepidophyma flavimaculatum (NC_008775), Sceloporus occidentalis (NC_005960), Takydromus tachydromoides (NC_008773). 
However, the rationale that $\mathrm{D}_{\text {ssh }} \mathrm{r}->\mathrm{D}_{\text {ssh }}$ convergence affects both lifespan and gestation yields a prediction that is not trivial, despite the strong positive correlation that exists between lifespan and the length of the gestation period: in groups of species with high fertility and rates of development (short gestation), considered as r-strategists, one expects that $D_{\text {ssh }} r->D_{\text {ssh }}$ t convergence adaptively coevolved with the length of gestation, while in groups of species with low fertility and rates of development (long gestation and lifespan), considered as K-strategists, it makes sense to expect adaptive coevolution between $\mathrm{D}_{\mathrm{ssh}} \mathrm{r}$ $>\mathrm{D}_{\text {ssh }} \mathrm{t}$ convergence and lifespan. Hence, despite that lifespan and the length of gestation are highly correlated, a testable, independent, nontrivial prediction exists, which is that correlations between $\mathrm{D}_{\text {ssh }} \mathrm{r}->\mathrm{D}_{\text {ssh }} \mathrm{t}$ convergence and lifespan should be weaker in $\mathrm{r}$ strategists than those between $D_{\text {ssh }} r->D_{\text {ssh }} t$ convergence and the length of gestation, while in $K$ strategists, the opposite is expected. This is estimated by subtracting the $\mathrm{z}$ transformed correlation coefficient between $\mathrm{D}_{\mathrm{ssh}} \mathrm{r}->\mathrm{D}_{\text {ssh }} \mathrm{t}$ convergence and the length of gestation from the $\mathrm{z}$ transformed correlation coefficient between $\mathrm{D}_{\mathrm{ssh}} \mathrm{r}->\mathrm{D}_{\text {ssh }} \mathrm{t}$ convergence and lifespan in that group ( $\mathrm{z}$ transformation was adjusted for differences in sample sizes between different

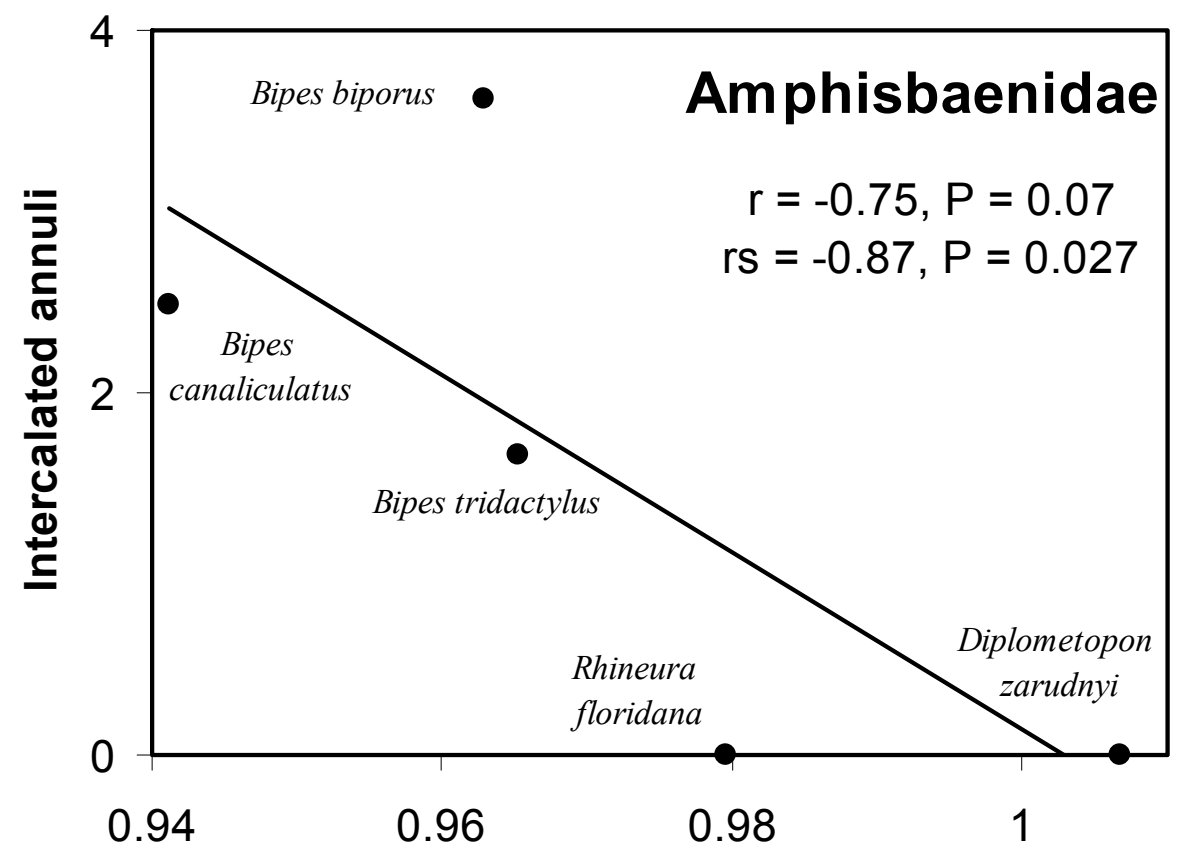

\section{Colinearity between gradients +1}

Fig. 8. Number of intercalated annuli on the ventral side of Amphisbaenidae, a measure of developmental instability in serpentiform reptile species (see Seligmann and Krishnan 2006), as a function of colinearity between replication and transcription. $\mathrm{X}$ axis is as in Figure 4. Species names are followed by NCBI (genbank) entries: Bipes biporus (NC_006287); Bipes canaliculatus (NC_006288); Bipes tridactylus (NC_006286), Diplometopon zarudnyi (NC_006283) and Rhineura floridana (NC_006282). 


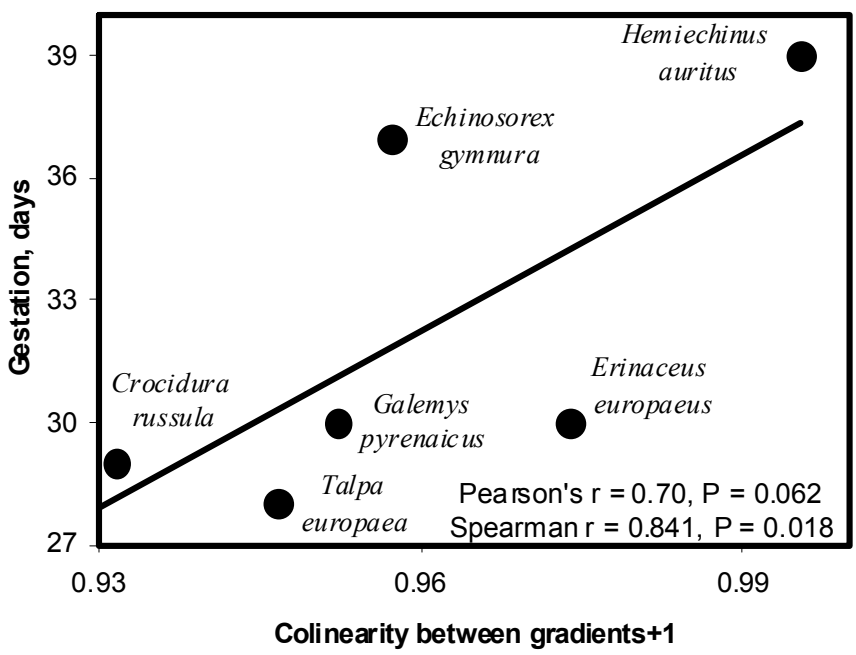

Fig. 9. Gestation period as a function of a measure of convergence between replication and transcription in mitochondrial genomes of Insectivora. X-Axis is as in Figure 3. Species names are followed by NCBI (genbank) entries: Crocidura russula, NC_006893; Echinosorex gymnura, NC_002808; Erinaceus europaeus, NC_002080; Galemys pyrenaicus, NC_008156; Hemiechinus auritus, NC_005033; Talpa europaea, NC_002391.

taxonomic groups, see method in Seligmann et al., 2007). Figure 10 tests this prediction by plotting this subtraction as a function of the mean maximal lifespan for that taxonomic group, used here as an estimate of the extent that the group is a relatively $\mathrm{r}$ - or K-strategist (short and long maximal lifespans, respectively). Results in Figure 10 fit the expectation that correlations with lifespan, relative to those with the length of the gestation period, increase along the $\mathrm{r}-\mathrm{K}$ gradient. The increase in the subtraction is approximately gradual along the $\mathrm{r}-$ $\mathrm{K}$ gradient (which is estimated by the mean maximal lifespan in that group). According to this result, patterns from more than 100 mitochondrial genomes follow the complex predictions from a simple hypothesis.

\section{General discussion}

\subsection{Replication versus transcription gradients in various species}

Results show that species vary widely in extents of convergence between replication and transcription gradients. In many species, the replication gradient starting at the recognized $\mathrm{OL}$ is the only or the major gradient detected, as found for Crocidura (Figure 2a). In these species, no gradient resembling the transcription gradient, whether due to transcription or replication, was detected. This observation, considering that transcription occurs in all species, suggests that most mutations on mitochondrial DNA occur during replication. The lack of detection of gradients that resemble what could be interpreted as a transcriptionrelated gradient suggests that in those fewer species where significant correlations occur between nucleotide contents and $\mathrm{D}_{\text {ssh }} \mathrm{t}$, these reflect mutations occurring during replication, 


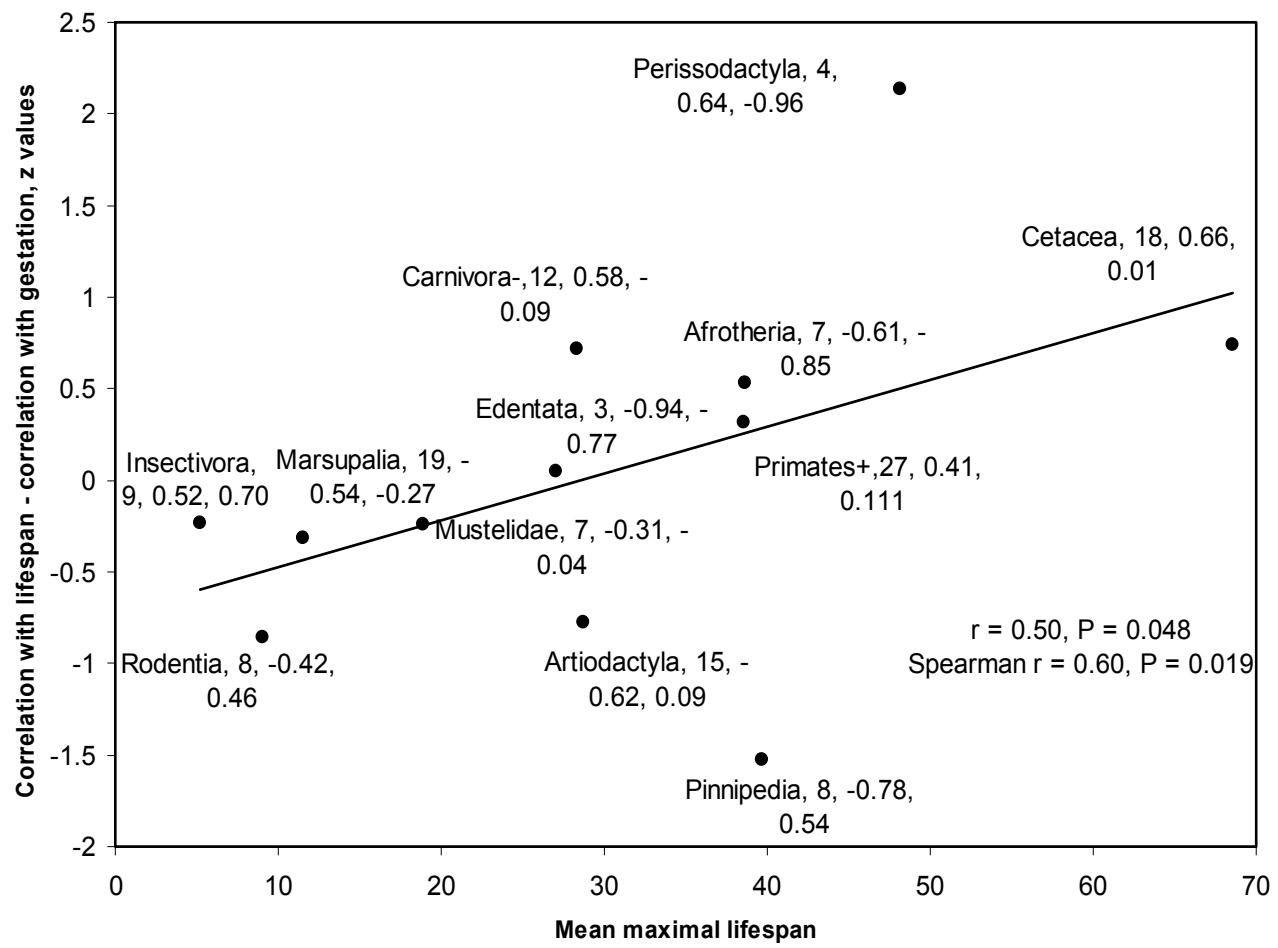

Fig. 10. Difference between strength of association of convergence between replication and transcription gradients with maximal lifespan and with length of gestation period as a function of the mean maximal lifespan in that mammalian taxonomic group. For each taxonomic group, the Pearson correlation coefficient of gradient convergence with length of gestation in that group was subtracted from its correlation coefficient with maximal lifespan. Group names are indicated near datapoints, followed by the number of species used for the lifespan analyses, and the correlation coefficients with lifespan and length of gestation, respectively. Values used for the $y$ axis, but not for those indicated inside the figure, are $\mathrm{z}$ transformed correlation coefficients, taking into account sample sizes (see text). Carnivoraindicates that analyses were done excluding Mustelidae and Pinnipedia, and Primates+ indicates that analyses of this group included Cynocephalus and Tupaia.

with replication origins distributed such that the overall replicational gradient (integrating over different replication origins) resembles the one caused by transcription. It is possible that because transcription is much more frequent than replication, the reactions that create the gradients are saturated, and hence no gradient is detected at the time scales the phenomenon is observed here. Hence while the comparative methodology used seems adequate to detect replication gradients, other methods should be used in order to detect transcription gradients. This means that at this evolutionary time scale, replication is the main phenomenon, and transcription is probably a secondary phenomenon, whose detection necessitates more sophisticated methods, as explained for some cases from the literature in the Introduction. 
The correlation between convergence of replication gradient with transcription gradient with lifespan was $r=0.80$ in Chiroptera ( 5 species), but this group is not included in Figure 10 because only for 2 Chiroptera both genomic and gestation period data were available. Results presented for lizards (Figure 9) are not included because there is no gestation per se in these groups.

\subsection{Transcription or replication?}

For the sake of simplicity, I consider that the major cause for the observed gradients in nucleotide contents with $\mathrm{D}_{\mathrm{ssh}} \mathrm{t}$ is replication, meaning that in these cases replication converged with transcription, but that transcription itself is not responsible for the observed gradients. Although this is at this point a rough simplification, there are several reasons beyond those given above justifying this assumption. It makes sense that the polymerization rates by the gamma polymerase, the enzyme replicating mitochondrial DNA, and by the mitochondrial RNA polymerase (Bonawitz et al., 2006) differ, because these are very different enzymes and the functional requirements differ for each process: the frequency of transcription is much greater than that of replication, and its rate is also probably much greater. However, the impact of errors during RNA polymerization is lower than that during DNA replication and hence RNA and DNA polymerase fidelities are also probably very different. Deamination gradients result from time spent single stranded during these processes, but because one can assume that transcription is much faster than replication, it is likely that the properties of the mutation gradient resulting from transcription differ from those of the replication gradient. Hence effects of one $D_{\text {ssh }}$ unit on nucleotide contents should differ between gradients caused by transcription or replication. Examining the various graphs in Figure 2, one can see that this is not the case: the slopes found for gradients with $\mathrm{D}_{\text {ssh }} \mathrm{rW}$ and $\mathrm{D}_{\text {ssh }}$ are very similar when gradients are detected with each $\mathrm{D}_{\text {ssh }} \mathrm{rW}$ and $\mathrm{D}_{\text {ssh }}$ (see for example the western gorilla, Figure 2b). This justifies the simplifying assumption that replication is the major cause of the observed gradients, and this approach should be considered as a satisfying approximation at this point.

This does not mean that this assumption should not be tested later, especially that exploring this issue might yield valuable information on the relative regulations of transcription, replication, and/or various types of replication, which are at the heart of the mitochondrial replication controversy and ageing-related pathologies. Note that even at that level of distinguishing between deamination gradients caused by transcription and those caused by replication in a situation where both are confounded because replication is collinear with transcription, bioinformatics analyses can be helpful. Two deamination gradients exist on the heavy strand, one caused by the chemical reaction $\mathrm{C}->\mathrm{T}$, and one by A->G (both hydrolytic deaminations). The former is the faster reaction, and therefore the latter saturates less quickly, also from an evolutionary point of view (see Krishnan et al., 2004a, b). Therefore each of these two mutation types reacts differently to $\mathrm{D}_{\text {ssh. }}$. Hence the ratio between the slopes of each of these gradients should differ if the gradients are due to transcription (C->T should be less saturated and more similar to the A-> G gradient because transcription is faster than replication) than when deamination gradients are due to replication. Hence such analyses could determine which process, transcription or replication, created the detected gradient(s), even when both processes are collinear and apparently confounded. 


\subsection{Gradient convergence and lifespan in Primates}

Results in Figure 3 suggest that convergence between replication and transcription slows ageing-related processes in Primates. Note that Figure 3 shows that relative to other Primates, longevity in Homo sapiens is greater than expected according to convergence between replication and transcription. This would be congruent with the hypothesis that human longevities increased recently, due to factors other than convergence of $D_{\text {ssh }} r->D_{s s h} t$, but suggests that future evolution increasing this convergence could still increase longevity. The correlation in Figure 3 also remains significant after applying the method of phylogenetic contrasts (Felsenstein, 1985) to the data, suggesting that the results are statistically valid independently of phyletic constraints $(r=0.50, P=0.03$, one tailed test). It makes sense that results of regular correlations, with and without accounting for phylogenetic contrasts are qualitatively similar because evolution of tRNAs functioning as OLs tends to be saltatory (Seligmann et al., 2006b).

Gestation time, despite its association with maximal lifespan in Primates $(r=0.67, \mathrm{P}<0.01)$, only slightly increases with the level of $\mathrm{D}_{\text {ssh }} \mathrm{r}->\mathrm{D}_{\text {ssh }}$ convergence $(\mathrm{r}=0.11, \mathrm{P}<0.1)$. This suggests that collinearity between replication and transcription might cause interferences, slowing down both processes and ultimately developmental rates. Even a weak effect on developmental rates (inversely proportional to gestation length) could be a potent selective pressure in natural populations, counterbalancing pressures against cumulating excess mutations that favor collinearity between the processes.

This effect on growth rates is probably relatively weak in Primates and in general Kstrategists, which maximize lifespan rather than developmental rates (Brookfield, 1986). The opposite is expected in groups that are, relatively to Primates, more r-strategy-oriented, a strong prediction corroborated in Figure 10 and discussed below.

\subsection{Correlations between molecular and whole organism levels}

One should note that several correlations between life history parameters and molecular indices characterizing metabolic strategies of cells have already been described, specifically for Primates: the length of the gestation period with cost minimization of nuclear amino acid usages (Seligmann, 2003), cost minimization of mitochondrial ribosomal frameshifts (Seligmann \& Pollock, 2004), slopes of (regular) mitochondrial replication gradients (Raina et al., 2005); and now maximal lifespan with convergence between mitochondrial replication and transcription. Seligmann \& Krishnan (2006) discuss how whole organism properties probably result from many different, coadapted cellular processes, so that the wealth of significant correlations detected between molecular properties and whole organism features should be of no surprise. In addition, it is notable that nuclear genome size is not related to life-history traits in Primates (Morand \& Ricklefs, 2005), so that effects of mitochondrial properties are more likely to be detected in this group.

\subsection{Too extreme convergence between replication and transcription}

The examination of Figures 3 and 4 shows that the trend between maximal lifespan and $\mathrm{D}_{\text {ssh }} \mathrm{r}->\mathrm{D}_{\text {ssh }} \mathrm{t}$ convergence has outliers, and that these outliers are usually placed in the same relative area of the graph: these are species with relatively high convergence but lower than expected lifespan. It is possible that this situation results from asymmetry in inaccuracies in maximal lifespan estimations, as sampling error can only cause lower values than the real maximal lifespan. However it makes little sense that the well studied Macaca species, for 
example, have a lifespan that is much greater than in Figure 3, although these species are clearly outliers in respect to the general trend in Figure 3. This situation was also observed in other taxonomic groups (results not presented graphically here but used in Figure 10), and it is remarkable that there were never cases of outliers with low convergence but high lifespan. Hence the hypothesis of statistical artifact is unlikely here, and this situation is most probably biologically meaningful. It indicates that low convergence between replication and transcription does not enable to reach a long lifespan, but that high convergence is not necessarily a sufficient condition to enable a long lifespan, and that other factors affect this. The results for Cetacea (Figure 5) indeed show that high convergence might in fact limit lifespan. Presumably, this is because at high convergence levels, the decrease in mutations due to collinearity between replication and transcription might be smaller than the increase due to longer $D_{\text {ssh }}$ because of increasing delays due to collisions between replication and transcription. This could explain the relatively sharp boundary between the region where convergence increases lifespan, and the one where a negative correlation is observed in Cetacea, and would account for outliers in figures presenting results for other taxa.

\subsection{Rates of development and convergence between replication and transcription}

The hypothesis that collisions decrease rates of replication and transcription when both processes are collinear predicts that rates of development decrease with $D_{s s h} r->D_{s s h} t$ convergence. The cause for this would differ from the correlation between $D_{\text {ssh }} r->D_{\text {ssh }} t$ convergence and lifespan. For lifespan, convergence decreases cumulation of mutations and in general, increases mutational robustness; for developmental rates, they are the direct result of decreased replication and transcription rates because of increased collision frequencies between replication and transcription forks. It is notable that this rationale yields a molecular mechanism for the well known negative association between metabolic rates and longevities, as described in Insects (Antler flies, Bonduriansky \& Brassil, 2005; Drosophila, Marden et al., 2003; Novoseltsev et al., 2005; Mockett \& Sohal, 2006), nematodes (Jenkins et al., 2004; Chen et al., 2007; Lee et al., 2006; Hughes et al., 2007) and mice (Cargill et al., 2003; and others, Bonsall, 2006). Some ecological data explaining the tradeoffs exist (Bonduriansky \& Brassil, 2005), and results suggest the tradeoff is due to dietary metabolism (Partridge et al., 2005a,b; Speakman, 2005a,b; Kaeberlein et al. 2006; Ruggiero \& Ferrucci, 2006; Szewczyk et al., 2006; Wolkow \& Iser, 2006). Other evidence shows that this rule might not be universal (Van Voorhies et al., 2004; Khazaeli et al., 2005; Johnston et al., 2006), stressing the need for unifying hypotheses. Several molecular or biochemical mechanisms have been proposed (Balaban et al., 2005; Bartke ,2005; Knauf et al., 2006; Powers et al., 2006 ) but no general molecular model exists, stressing the importance to link the $D_{\text {ssh }} r->D_{\text {ssh }} t$ convergence hypothesis with the lifespan-growth rate tradeoff. Making a meaningful test for this prediction that $\mathrm{D}_{\text {ssh }} \mathrm{r}->\mathrm{D}_{\text {ssh }} \mathrm{t}$ convergence decreases developmental rates (hence increases the length of gestation) is not straightforward because of the strong positive association that exists between maximal lifespan and gestation length. However, using evolutionary ecology theory on $\mathrm{r}$ and $\mathrm{K}$ strategists, the simple molecular mechanism makes complex predictions on the relative strengths of association of $D_{\text {ssh }} r->D_{\text {ssh }} t$ convergence with lifespan and gestation length, respectively. The fact that these predictions are overall verified by the analysis of a large number of species and groups of species in Figure 10 is strong support for the $D_{\text {ssh }} r->D_{\text {ssh }}$ convergence hypothesis and its coevolution with major life history traits. 


\subsection{Causal interpretations of correlations between lifespan and convergence between replication and transcription}

The hypothesis that collisions decrease rates of replication and transcription when both processes are collinear enables to predict the occurrence of species that seem outliers in graphical analyses. However, the longevity-growth rate tradeoff hypothesis suggests the possibility that the causal interpretation of the association of $\mathrm{D}_{\text {ssh }} \mathrm{r}->\mathrm{D}_{\text {ssh }}$ t convergence with maximal lifespan is opposite to the direction assumed. This is because offspring fitness decreases with parental age (Kern, 2001; Priest et al., 2002; Moore \& Harris, 2003; Moore \& Sharma, 2005), putatively due to ontogenetic cumulation of mutations, especially in mothers (McIntyre \& Gooding, 1998; Hercus \& Hoffmann, 2000), which are inherited by offspring. This issue is particularly relevant to mitochondria. Indeed, species with long lifespan probably have relatively high transcription/replication ratios. Hence what appears to be convergence of replication gradients towards transcription gradients could be the result of increased lifespan, rather than its cause. This interpretation assumes that the gradients observed are transcription-, rather than replication ones, which remains possible despite the arguments against this in previous sections. Notwithstanding these arguments, this interpretation is not compatible with other predictions presented here about developmental rates, the relatively frequent outlying species characterized by high convergence and lower than expected lifespan, and the threshold phenomenon observed in Figure 5. In addition, this individual-based observation is a stabilizing feedback mechanism where increased longevity causes inheritance of mutations that decrease offspring longevity. This would rather predict negative correlations, or no correlation at time scales larger than that of single generations, such as in the inter-species comparisons described in the Results.

The specific situation in Homo, where recent evolution caused a rapid increase in lifespan that is not paralleled by a proportionately high $D_{\text {ssh }} r->D_{\text {ssh }}$ convergence, could be interpreted both ways: lifespan, which is known to have increased recently by man-made environmental changes and not cell metabolism (Larkin, 2000), does not fit what would be expected according to cell metabolism (as measured by $\mathrm{D}_{\text {ssh }} \mathrm{r}->\mathrm{D}_{\text {ssh }} \mathrm{t}$ convergence), suggesting that in other species where no such fast changes occurred, $D_{\text {ssh }} r->D_{s s h} t$ convergence explains lifespan. Alternatively, one could speculate that in Homo, the recent man-made increase in lifespan did not yet alter the relative strengths of transcription versus replication gradients, following the hypothesis that a long lifespan increases more the number of transcriptions than of replication. According to that scenario, the relatively recently increased transcription/replication ratio did not yet result in stronger transcription gradients in Homo, explaining the position of that species in Figure 3. Besides that the latter interpretation is based on a more complex rationale than the former, it also seems less likely because if the causal mechanism underlying the $\mathrm{D}_{\text {ssh }} \mathrm{r}->\mathrm{D}_{\text {ssh }} \mathrm{t}$ convergence-lifespan association is that increased lifespan causes more transcription-related deaminations, this is due to mutations cumulating ontogenetically (see the effects of parental age on offspring quality referred to above). However, following this rationale, gradients should almost immediately react to the increase in lifespan, which is not the case in Homo.

\subsection{Developmental stability and convergence between transcription and replication}

It is interesting to note that the principles observed for the association between $D_{s s h} r->D_{s s h} t$ convergence and lifespan are also valid for that between $\mathrm{D}_{\mathrm{ssh}} \mathrm{r}->\mathrm{D}_{\mathrm{ssh}} \mathrm{t}$ convergence and developmental stability. This observation fits the general trend that developmental 
instability associates with low fitness and pathologies. It would be interesting to explore whether this hypothesis of convergence of replication with transcription fits with the "double-agent" unifying hypothesis of ageing and diseases based on the tradeoff between oxidative stress inducing genetic reaction mechanisms against stress and its effect on ageing and age-related disease (Lane, 2003). The molecular processes presented provide mechanistic explanations for these similarities.

\section{Conclusions}

I present the original hypothesis that heavy strand sequences of tRNA-coding genes functioning as additional light strand replication origins tend to increase the similarity of mutational patterns resulting from replication with those due to transcription, putatively decreasing cumulation of mutations during the two processes. Variation exists among mitochondrial genomes in the extent that replication mutation gradients resemble transcription gradients; in most species (mainly short lived with high metabolism), replication gradients do not resemble transcription gradients. The similarity of replication mutation gradients to transcription ones correlates positively with maximal lifespan in Primates and other taxa. Systematically, outliers to these trends have replication mutation gradients relatively resembling transcription gradients but are for short lived species, the opposite (long lived outliers with replication gradients not resembling transcription gradients) does not occur. In some taxa such as Cetacea, this phenomenon is enhanced with two clearcut ranges in similarity between replication and transcription, one with relatively low similarities, where maximal lifespan increases with the similarity of replication gradients to transcription gradients, and another region where similarities are highest and maximal lifespan decreases with similarity. These patterns suggest that low convergence does not enable high maximal lifespans, but too high convergence limits lifespan, probably because too many collisions between replication and transcription forks decrease both replication and transcription rates, increasing durations spent single stranded, and mutation frequencies. The length of gestation periods increases also with convergence, notably, in $r$ strategists; in K strategists, the convergence levels coevolve more with maximal lifespan, fitting the rationale that the molecular machinery is adapted for high metabolism and fertility in $\mathrm{r}$ strategists, and high survival in K strategists. Results are interpreted assuming that the observed phenomena are due to replication that sometimes resembles transcription, but are not due to transcription. Evidence supporting this is presented: in species possessing two gradients, one according to the classical replication origin, and one resembling transcription, both mutation gradients have very similar slopes, which is more compatible with a single enzymatic machinery (the mitochondrial gamma DNA polymerase) causing both gradients, rather than each due to a different polymerase. A method based on differences in the respective rates of replication and transcription for distinguishing between replication and transcription gradients is suggested, where the ratios between slopes of mutation gradients of purines versus pyrimidines should vary when mutation gradients are due to replication resembling transcription rather than transcription itself. The hypothesis that results are due to a causal relationship opposite to the one proposed (high longevity causes high transcription/replication ratios and hence transcription gradients dominate replication ones) is examined and discussed. This interpretation is unlikely, not only because gradients seem to be due to a single enzymatic process, but also because this hypothesis is less compatible with patterns in the data: among others it does not predict the patterns observed for outliers and the differences between $r$ - and K-strategists. 


\section{Acknowledgments}

I am very thankful to Neeraja M. Krishnan for manifold help in the preparation and improvement of this manuscript. Morphological data could not have been gathered without considerable curatorial help at the various herpetological collections I visited: American Museum of Natural History, New York; California Academy of Sciences, San Francisco; Field Museum, Chicago; Hebrew University of Jerusalem; Museum of Natural History, London; Museum of Vertebrate Zoology, Berkeley; Peggy Notebaert Nature Museum, Chicago Academy of Sciences; Tel Aviv University.

\section{References}

Albrecht-Buehler, G. (2006) Asymptotically increasing compliance of genomes with Chargaff's second parity rules through inversions and inverted transpositions. Proc. Nat. Acad. Sci. USA, 103, 17828-17833.

Aldana, M., Balleza, E., Kauffman, S., Resendiz, O. (2007) Robustness and evolvability in genetic regulatory networks. J. Theor. Biol. 245, 433-448.

Amzallag, G.N. (2001) Data analysis in plant physiology: are we missing the reality? Plant Cell. Env. 24, 881-890.

Balaban, R.S., Nemoto, S., Finkel, T. (2005) Mitochondria, oxidants, and aging. Cell 120, 483495.

Baran, R.H., Ko, H., Jernigan, R.N. (2003) Methods for comparing sources of strand compositional asymmetry in microbial chromosomes. DNA Res. 10, 85-95.

Bartke, A. (2005) Minireview: Role of the growth hormone/insulin-like growth factor system in mammalian aging. Endocrinology 146, 3718-3723.

Bonawitz, N.D., Clayton, D.A., Shadel, G.S. (2006) Initiation and beyond: multiple functions of the human mitochondrial transcription machinery. Mol. Cell. 24, 813-825.

Bonduriansky, R., Brassil, C.E. (2005) Reproductive ageing and sexual selection on male body size in a wild population of antler flies (Protopiophila litigata). J. Evol. Biol. 18, 1332-1340.

Bonsall, M.B. (2006) Longevity and ageing: appraising the evolutionary consequences of growing old. Phil. Trans. Royal Soc. B-Biol. Scie. 361, 119-135.

Boulikas, T. (1995) A model of transcription replication enhancers. Oncol. Rep. 2, 171-181.

Brazhnik, P., Tyson, J.J. (2006) Cell cycle control in bacteria and yeast - A case of convergent evolution? Cell Cycle 5, 522-529.

Brookfield, J.F.Y. (1986) The evolution of r-strategies and K-strategies. Biol. J. Linn. Soc. 27, 165-178.

Brown, T.A., Clayton, D.A. (2006) Genesis and wanderings - Origins and migrations in asymmetrically replicating mitochondrial DNA. Cell Cycles 5, 917-921.

Brown, T.A., Cecconi, C., Tkachuk, A.N., Bustamante, C., Clayton, D.A. (2005) Replication of mitochondrial DNA occurs by strand displacement with alternative light-strand origins, not via a strand-coupled mechanism. Genes \& Dev. 19, 2466-2476.

Cargill, S.L., Carey, J.R., Muller, H.G., Anderson, G. (2003) Age of ovary determines remaining life expectancy in old ovariectomized mice. Aging Cell 2, 185-190.

Chang,D.D., Clayton,D.A. (1984) Precise identification of individual promoters for transcription of each strand of human mitochondrial DNA. Cell 36, 635-643. 
Chang, D.D., Clayton, D.A. (1985) Priming of human mitochondrial DNA replication occurs at the light-strand promoter. Proc. Natl. Acad. Sci. USA 82, 351-355.

Chang, D.D., Hauswirth, W.W., Clayton, D.A. (1985) Replication priming and transcription initiate from precisely the same site in mouse mitochondrial DNA. EMBO J. 4: 15591567.

Chen, J.J., Senturk, D., Wang, J.L., Muller, H.G., Carey, J.R., Caswell, H., Caswell-Chen, E.P. (2007) A demographic analysis of the fitness cost of extended longevity in Caenorhabditis elegans. J. Geront. A-Biol. Scie. E Med. Scie. 62, 126-135.

Ciliberti, S., Martin, O.C., Wagner, A. (2007) Robustness can evolve gradually in complex regulatory gene networks with varying topology. PLOS Comp. Biol. 3, 164-173.

Clayton, D.A. (2000) Transcription and replication of mitochondrial DNA. Hum. Reprod. 15, 11-17.

Clayton, D.A., Brown, T.A. (2006) Replication of mammalian mitochondrial DNA occurs by strand displacement with alternative light-strand origins. FASEB J 20, A453-A453.

Coskun, P.E., Beal, M.F., Wallace, D.C. (2004) Alzheimer's brains harbor somatic mtDNA control-region mutations that suppress mitochondrial transcription and replication. Proc. Nat. Ac. Sci. USA 101, 10726-10731.

Couturier, E., Rocha, E.P.C. (2006) Replication-associated gene dosage effects shape the genomes of fast-growing bacteria but only for transcription and translation genes. Mol. Microbiol. 59, 1506-1518.

de Magalhaes, J. P., and Costa, J. (2009) A database of vertebrate longevity records and their relation to other life-history traits. J. Evol. Biol. 22, 1770-1774.

Desjardins, P., Morais, R. (1990) Sequence and gene organization of the chicken mitochondrial genome - a novel gene order in higher vertebrates. J. Mol. Biol. 212, 599-634.

Elena, S.F., Wilke, C.O., Ofria, C., Lenski, R.E. (2007) Effects of population size and mutation rate on the evolution of mutational robustness. Evolution 61, 666-674.

Feder, M.E. (2007) Evolvability of physiological and biochemical traits: evolutionary mechanisms including and beyond single-nucleotide mutation. J. Exp. Biol. 210, 1653-1660,

Felsenstein, J. (1985) Phylogenies and the comparative method. Am. Nat. 125, 1-15.

Fernandez-Silva, P., Enriquez, J.A., Montoya, J. (2003) Replication and transcription of mammalian mitochondrial DNA. Exp. Physiol. 88, 41-56.

Francino, M.P., Chao, L., Riley, M.A., Ochman, H. (1996) Asymmetries generated by transcription-coupled repair in enterobacterial genes. Science 272, 107-109.

Francino, M.P., Ochman, H. (2001) Deamination as the basis of strand-asymmetric evolution in transcribed Escherichia coli sequences. Mol. Biol. Evol. 18, 1147-1150.

Gibson, A.P. (2005) Comparative analysis of vertebrate mitochondrial genomes. PhD thesis, University of Manchester, UK.

Gilbert, D.M. (2001) Making sense of eukaryotic DNA replication origins. Science 294, 96-100.

Glusman, G., Qin, S.Z., El-Gewely, R., Siegel, A.F., Roach, J.C., Hood, L., Smit, A.F.A. (2006) A third approach to gene prediction suggests thousands of additional human transcribed regions. PLOS Comp. Biol. 2, 160-173.

Grigoriev, A. (1999) Strand-specific compositional asymmetries in double-stranded DNA viruses. Virus Res. 60, 1-19. 
Hassan, A.B., Cook, P.R. (1994) Does transcription by RNA-polymerase play a direct role in the initiation of replication? J. Cell. Sci. 107, 1381-1387.

Hassanin, A., Leger, N., Deutsch, J. (2005) Evidence for multiple reversals of asymmetric mutational constraints during the evolution of the mitochondrial genome of Metazoa, and consequences for phylogenetic inferences. Syst. Biol. 54, 277-298.

Hercus, M.J., Hoffmann, A.A. (2000) Maternal and grandmaternal age influence offspring fitness in Drosophila. Proc. Royal Soc. London B-Biol. Scie. 267, 2105.

Holt, I.J., Lorimer, H.E., Jacobs, H.T. (2000) Coupled leading- and lagging-strand synthesis of mammalian mitochondrial DNA. Cell 105, 515-524.

Hou, W.R., Wang, H.F., Niu, D.K. (2006) Replication-associated strand asymmetries in vertebrate genomes and implications for replicon size, DNA replication origin, and termination. Biochem. Biophys. Res. Comm. 344, 1258-1262.

Hughes, S.E., Evason, K., Xiong, C.J., Kornfeld, K, (2007) Genetic and pharmacological factors that influence reproductive aging in nematodes. PLOS Genetic 3, 254-265.

Huvet, M., Nicolay, S., Touchon, M., Audit, B., d'Aubenton-Carafa, Y., Arneodo, A., Thermes, C., (2007) Human gene organization driven by the coordination of replication and transcription. Genom. Res. 17, 1278-1285.

Jenkins, N.L., McColl, G., Lithgow, G.J. (2004) Fitness cost of extended lifespan in Caenorhabditis elegans. Proc. Royal Soc. London B-Biol. Scie. 271, 2523-2526.

Jones, A.G., Arnold, S.J., Burger, R. (2007) The mutation matrix and the evolution of evolvability. Evolution 61, 727-745.

Jones, K.E., MacLarnon, A.M. (2004) Affording larger brains: Testing hypotheses of mammalian brain evolution on bats. Amer. Nat. 164, E20-E31.

Johnston, S.L., Grune, T., Bell, L.M., Murray, S.J., Souter, D.M., Erwin, S.S., Yearsley, J.M., Gordon, I.J., Illius, A.W., Kyriazakis, I., Speakman, J.R. (2006) Having it all: historical energy intakes do not generate the anticipated trade-offs in fecundity. Proc. Royal. Soc. B-Biol. Scie. 273, 1369-1374.

Kaeberlein, T.L., Smith, E.D., Tsuchiya, M., Welton, K.L., Thomas, J.H., Fields, S., Kennedy, B.K., Kaeberlein, M. (2006) Lifespan extension in Caenorhabditis elegans by complete removal of food Aging Cell 5, 487-494.

Kern, S., Ackermann, M., Stearns, S.C., Kawecki, T.J. (2001) Decline in offspring viability as a manifestation of aging in Drosophila melanogaster. Evolution 55, 1822-1831.

Khaidakov, M., Siegel, E.R., Reis, R.J.S. (2006) Direct repeats in mitochondrial DNA and mammalian lifespan. Mech. Ageing Dev. 127, 808-812.

Khazaeli, A.A., Van Voorhies, W., Curtsinger, J.W. (2005) Longevity and metabolism in Drosophila melanogaster: Genetic correlations between life span and age-specific metabolic rate in populations artificially selected for long life. Genetics 169, 231-242.

Knauf, F., Mohebbi, N., Teichert, C., Herold, D., Rogina, B., Helfand, S., Gollasch, M., Luft, F.C., Aronson, P.S. (2006) The life-extending gene Indy encodes an exchanger for Krebs-cycle intermediates. Biochem. J. 397, 25-29.

Krishnan, N.M, Seligmann, H., Raina, S.Z., Pollock, D.D. (2004a) Detecting gradients of asymmetry in site-specific substitutions in mitochondrial genomes. DNA Cell Biol. 23, 707-714.

Krishnan N.M, Seligmann, H., Raina, S.Z., Pollock, D.D. (2004b) Phylogenetic analyses detect site-specific perturbations in asymmetric mutation gradients. Curr. Computa. Mol. Biol. 2004, 266-267. 
Larkin, M. (2000) Is the human lifespan limitless? Lancet 356, 1249-1249.

Lane, N. (2003) A unifying view of ageing and disease: the double-agent theory. J. Theor. Biol. 225, 531-540.

Lee, D.Y., Clayton, D.A. (1997) RNase mitochondrial RNA processing correctly cleaves a novel R loop at the mitochondrial DNA leading-strand origin of replication. Genes Dev. 11,582-592.

Lee, G.D., Wilson, M.A., Zhu, M., Wolkow, C.A., de Cabo, R., Ingram, D.K., Zou, S.G. (2006) Dietary deprivation extends lifespan in Caenorhabditis elegans. Aging Cell 5, 515-524.

Little, R.D., Platt, T.H.K., Schildkraut, C.L. (1993) Initiation and termination of DNA replications in human ribosomal-RNA genes. Mol. Cell Biol. 13, 6600-6613.

MacAlpine, D.M., Rodriguez, H.K., Bell, S.P. (2004) Coordination of replication and transcription along a Drosophila chromosome. Genes Dev. 18, 3094-3105.

Macey, J.R., Larson, A., Ananjeva, N.B., Fang, Z., Papenfuss, T.J. (1997) Two novel gene orders and the role of light-strand replication in rearrangement of the vertebrate mitochondrial genome. Mol. Biol. Evol. 14, 91-104.

Mackiewicz, P., Gierlik, A., Kowalczuk, M., Dudek, M.R., Cebrat, S. (1999) How does replication-associated mutational pressure influence amino acid composition of proteins? Genome Res. 9, 409-416.

Marczynski, G.T., Shapiro, L. (1995) The control of asymmetric gene-expression during Caulobacter cell-differentiation. Arch. Microbiol. 163, 313-321.

Martin, I., Grotewiel, M.S. (2006) Oxidative damage and age-related functional declines. Mech. Ageing Dev. 127, 411-423.

Marden, J.H., Rogina, B., Montooth, K.L., Helfand, S.L. (2003) Conditional tradeoffs between aging and organismal performance of Indy long-lived mutant flies. Proc. Nat. Acad. Scie. USA 100, 3369-3373.

McIntyre, G.S., Gooding, R.H. (1998) Effect of maternal age on offspring quality in tsetse (Diptera : Glossinidae). J. Med. Entom. 35, 210-215.

Mirkin, E.V., Mirkin, S.M. (2005) Mechanisms of transcription-replication collisions in bacteria. Mol. Cell Biol. 25, 888-895.

Mockett, R.J., Sohal, R.S. (2006) Temperature-dependent trade-offs between longevity and fertility in the Drosophila mutant, Methuselah. Exp. Geront. 41, 566-573.

Mohanty, B.K., Sahoo, T., Bastia, D. (1996) The relationship between sequence-specific termination of DNA replication and transcription. Embo J. 15, 2530-2539.

Moller, A.P. (1997) Developmental stability and fitness: A review. Am. Nat. 149:916-932.

Moller, A.P. (1999) Developmental stability is related to fitness. Am. Nat. 153:556-560.

Moore, P.J., Harris, W.E. (2003) Is a decline in offspring quality a necessary consequence of maternal age? Proc. Royal Soc. London B-Biol. Scie. 270: S192-S194.

Moore, P.J., Sharma, S. (2005) A delay in age at first mating results in the loss of future reproductive potential via apoptosis. Evol. E Dev. 7, 216-222.

Morand, S., Ricklefs, R.E. (2005) Genome size is not related to life-history traits in Primates. Genome 48: 273-278.

Morton, B.R. (1999) Strand asymmetry and codon usage bias in the chloroplast genome of Euglena gracilis. Proc. Nat. Acad. Sci. USA 96, 5123-5128.

Mrazek, J., Karlin, S. (1998) Strand compositional asymmetry in bacterial and large viral genomes. Proc. Nat. Acad. Sci. USA 95, 3720-3725. 
Nass, N.M.L. (1995) Precise sequence assignment of replication origin in the control region of chick mitochondrial-DNA relative to 5'-D-loop-ends and 3'-D-loop-ends, secondary structure, DNA-synthesis, and protein-binding. Curr. Genet. 28, 401-409.

Nikolaou, C., Almirantis, Y. (2005) A study on the correlation of nucleotide skews and the positioning of the origin of replication: different modes of replication in bacterial species. Nuc. Acids Res. 33, 6816-6822.

Novoseltsev, V.N., Arking, R., Carey, J.R., Novoseltseva, J.A., Yashin, A.I. (2005) Individual fecundity and sensescence in Drosophila and Medfly. J. Geront. 60A, 953-962.

Partridge, L., Gems, D., Withers, D.J. (2005a) Sex and death: What is the connection? Cell $120,461-472$.

Partridge, L., Piper, M.D.W., Mair, W. (2005b) Dietary restriction in Drosophila. Mechan. in Ageing \& Dev. 126, 938-950.

Patnaik, P.K. (1997) Studies with artificial extrachromosomal elements in trypanosomatids: Could specificity in the initiation of DNA replication be linked to that in transcription? Parasitol. Today 13, 468-471.

Pohjoismaki, J.L.O., Wanrooij, S., Hyvarinen, A.K., Goffart, S., Holt, I.J., Spelbrink, J.N., Jacobs, H.T. (2006) Alterations to the expression level of mitochondrial transcription factor A, TFAM, modify the mode of mitochondrial DNA replication in cultured human cells. Nuc. Acids Res. 34, 5815-5828.

Powers, R.W., Kaeberlein, M., Caldwell, S.D., Kennedy, B.K., Fields, S. (2006) Extension of chronological life span in yeast by decreased TOR pathway signaling. Genes $\mathcal{E}$ Dev. 20, 174-184.

Prado, F., Aguilera, A. (2005) Impairment of replication fork progression mediates RNA polII transcription-associated recombination. Embo J. 24, 1267-1276.

Priest, N.K., Mackowiak, B., Promislow, D.E.L. (2002) The role of parental age effects on the evolution of aging. Evolution 56, 927-935.

Rottenberg, H. (2006) Longevity and the evolution of the mitochondrial DNA-coded proteins in mammals. Mech. Ageing Dev. 127, 748-760.

Rottenberg, H. (2007) Coevolution of exceptional longevity, exceptionally high metabolic rates, and mitochondrial DNA-coded proteins in mammals. Exp. Geront. 42, 364373.

Ruggiero, C., Ferrucci, L. (2006) The endeavor of high maintenance homeostasis: Resting metabolic rate and the legacy of longevity. J. Geront. A-Biol. Scie. E Med. Scie. 61, 466-471.

Sacher, G.A., Staffeld, E.F. (1974) Relation of gestation time to brain weight for placental mammals - implications for theory of vertebrate growth. Amer. Nat. 108, 593-615.

Sade, D.S., Hildrech, R.W. (1965) Notes on Green Monkey (Cercopithecus aethiops sabaeus) on St. Kitts, West Indies. Caribbean J. Sci. 5, 65-81.

Samuels, D.C. (2004) Mitochondrial DNA repeats constrain the life span of mammals. TRIGS 20, 226-229.

Samuels, D.C. (2005) Life span is related to the free energy of mitochondrial DNA. Mech. Ageing Dev. 126, 1123-1129.

Samuels, D.C., Schon, E.A., Chinnery, P.F. (2004) Two direct repeats cause most human mtDNA deletions. TRIGS 20,393-398. 
Satoh , T.P., Sato, Y., Masuyama, N., Miya, M., Nishida, M. (2010) Transfer RNA gene arrangement and codon usage in vertebrate mitochondrial genomes: a new insight into gene order conservation. BMC Genomics 11, 479.

Schwaiger, M., Schubeler, D. (2006) A question of timing: emerging links between transcription and replication. Curr. Opin. Gen. \& Dev. 16, 177-183.

Szewczyk, N.J., Udranszky, I.A., Kozak, E., Sunga, J., Kim, S.K., Jacobson, L.A., Conley, C.A. (2006) Delayed development and lifespan extension as features of metabolic lifestyle alteration in C.elegans under dietary restriction. J. Exp. Biol. 209, 4129-4139.

Seligmann, H. (2003) Cost minimization of amino acid usage. J. Mol. Evol. 56, 151-151.

Seligmann, H. (2006) Error propagation across levels of organization: from chemical stability of ribosomal RNA to developmental stability. J. Theor. Biol. 242, 69-80.

Seligmann, H. (2010a) The ambush hypothesis at the whole-organism level: Off frame, 'hidden' stops in vertebrate mitochondrial genes increase developmental stability. Comp. Biol. Chem. 34, 80-85.

Seligmann, H. (2010b) Mitochondrial tRNAs as light strand replication origins: similarity between anticodon loops and the loop of the light strand replication origin predicts initiation of DNA replication. Biosystems 99, 85-93.

Seligmann, H., Krishnan, N.M. (2006) Mitochondrial replication origin stability and propensity of adjacent tRNA genes to form putative replication origins increase developmental stability in lizards. J. Exp. Zool. 306B, 433-439.

Seligmann, H., Krishnan, N.M., Rao, B.J. (2006a) Mitochondrial tRNA sequences as unusual replication origins: Pathogenic implications for Homo sapiens. J. Theor. Biol. 243, 375385.

Seligmann, H., Krishnan, N.M., Rao, B.J. (2006b) Possible multiple origins of replication in Primate mitochondria: alternative role of tRNA sequences. J. Theor. Biol. 241, 321332.

Seligmann, H., Pollock, D.D. (2004) The ambush hypothesis: hidden stop codons prevent off-frame gene reading. DNA \& Cell Biol. 23, 701-705.

Shadel, G.S., Clayton, D.A. (1997) Mitochondrial DNA maintenance in vertebrates. Ann. Rev. Biochem. 66, 409-435.

Speakman, J.R. (2005a) Body size, energy metabolism and lifespan. J. Exp. Biol. 208, 17171730.

Speakman, J.R. (2005b) Correlations between physiology and lifespan - two widely ignored problems with comparative studies. Aging Cell 4, 167-175.

Tanaka, M., Ozawa, T. (1994) Strand asymmetry in human mitochondrial mutations. Genomics 22, 327-335.

Touchon, M., Nicolay, S., Audit, B., Bordie of Brodie, E.B., d'Aubenton-Carafa, Y., Arneodo, A., Thermes, C. (2005) Replication-associated strand asymmetries in mammalian genomes: Toward detection of replication origins. Proc. Nat. Acad. Sci. USA 102, 9836-9841.

Van Voorhies, W.A., Khazaeli, A.A., Curtsinger, J.W. (2004) Testing the "rate of living" model: further evidence that longevity and metabolic rate are not inversely correlated in Drosophila melanogaster. J. Appl. Physiol. 97, 1915-1922.

Wagner, A., Wright, J. (2007) Alternative routes and mutational robustness in complex regulatory networks. Biosystems 88, 163-172. 
Werner, Y.L., Frankenberg, E., Volokita, M., Harari, R. (1993) Longevity of geckos (Reptilia, Lacertilia, Gekkonoidea) in captivity - an analytical review incorporating new data. Isr. J. Zool 39, 105-124.

Wich, S.A., Utami-Atmoko, S.S., Mitra Setia, T.M., Rijksen, H.D., Schuermann, C., van Hooff, J.A.R.A.M., van Schaik, C.P. (2004) Life history of wild Sumatran orangutans (Pongo abelii). J. Hum. Evol. 47, 385-398.

Wiesner, R.J.,, Zsurka, G., Kunz W. (2006) Mitochondrial DNA damage and the aging process-facts and imaginations. Free Radical Res. 40, 1284-1294.

Wolkow, C.A., Iser, W.B. (2006) Uncoupling protein homologs may provide a link between mitochondria, metabolism and lifespan. Ageing Res. Rev. 5, 196-208.

Xia, X., Huang, H., Carullo, M., Betrán, M., Moriyama, E.N. (2007) Conflict between translation initiation and elongationj in vertebrate genomes. PLoS 2, e227.

Yu, B.P., Chung, H.Y. (2006) Adaptive mechanisms to oxidative stress during aging. Mech. Ageing Dev. 127. 436-443. 


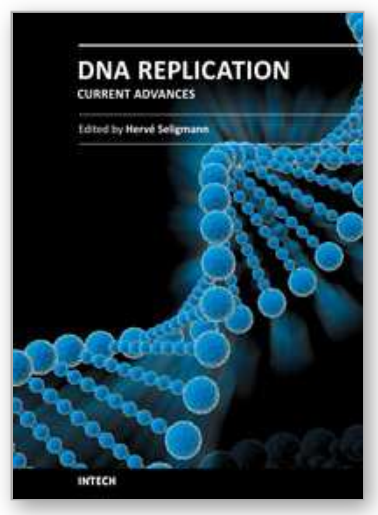

\section{DNA Replication-Current Advances}

Edited by Dr Herve Seligmann

ISBN 978-953-307-593-8

Hard cover, 694 pages

Publisher InTech

Published online 01, August, 2011

Published in print edition August, 2011

The study of DNA advanced human knowledge in a way comparable to the major theories in physics, surpassed only by discoveries such as fire or the number zero. However, it also created conceptual shortcuts, beliefs and misunderstandings that obscure the natural phenomena, hindering its better understanding. The deep conviction that no human knowledge is perfect, but only perfectible, should function as a fair safeguard against scientific dogmatism and enable open discussion. With this aim, this book will offer to its readers 30 chapters on current trends in the field of DNA replication. As several contributions in this book show, the study of DNA will continue for a while to be a leading front of scientific activities.

\section{How to reference}

In order to correctly reference this scholarly work, feel free to copy and paste the following:

Hervé Seligmann (2011). Mutation Patterns Due to Converging Mitochondrial Replication and Transcription Increase Lifespan, and Cause Growth Rate-Longevity Tradeoffs, DNA Replication-Current Advances, Dr Herve Seligmann (Ed.), ISBN: 978-953-307-593-8, InTech, Available from: http://www.intechopen.com/books/dnareplication-current-advances/mutation-patterns-due-to-converging-mitochondrial-replication-and-transcriptionincrease-lifespan-an

\section{INTECH}

open science | open minds

\section{InTech Europe}

University Campus STeP Ri

Slavka Krautzeka 83/A

51000 Rijeka, Croatia

Phone: +385 (51) 770447

Fax: +385 (51) 686166

www.intechopen.com

\section{InTech China}

Unit 405, Office Block, Hotel Equatorial Shanghai

No.65, Yan An Road (West), Shanghai, 200040, China

中国上海市延安西路65号上海国际贵都大饭店办公楼 405 单元

Phone: +86-21-62489820

Fax: +86-21-62489821 
(C) 2011 The Author(s). Licensee IntechOpen. This chapter is distributed under the terms of the Creative Commons Attribution-NonCommercialShareAlike-3.0 License, which permits use, distribution and reproduction for non-commercial purposes, provided the original is properly cited and derivative works building on this content are distributed under the same license. 